\title{
Multidimensional Biomarker Analysis Including Mitochondrial Stress Indicators for Nonalcoholic Fatty Liver Disease
}

\author{
Eunha Chang ${ }^{1,2}$, Jae Seung Chang ${ }^{2}$, In Deok Kong ${ }^{1}$, Soon Koo Baik ${ }^{2,3}$, Moon Young Kim²,3, and Kyu-Sang Park ${ }^{1,2}$ \\ ${ }^{1}$ Department of Physiology, ${ }^{2}$ Mitohormesis Research Center, and ${ }^{3}$ Department of Internal Medicine, Yonsei University Wonju College \\ of Medicine, Wonju, Korea
}

\section{Article Info}

Received March 10, 2021

Revised June 15, 2021

Accepted June 22, 2021

Published online August 24, 2021

Corresponding Author

Kyu-Sang Park

ORCID https://orcid.org/0000-0003-0322-9807

E-mail qsang@yonsei.ac.kr

Moon Young Kim

ORCID https://orcid.org/0000-0002-8566-2091

E-mail drkimmy@yonsei.ac.kr

\begin{abstract}
Nonalcoholic fatty liver disease (NAFLD) is accompanied by a complex and multifactorial pathogenesis with sequential progressions from inflammation to fibrosis and then to cancer. This heterogeneity interferes with the development of precise diagnostic and prognostic strategies for NAFLD. The current approach for the diagnosis of simple steatosis, steatohepatitis, and cirrhosis mainly consists of ultrasonography, magnetic resonance imaging, elastography, and various serological analyses. However, individual dry and wet biomarkers have limitations demanding an integrative approach for the assessment of disease progression. Here, we review diagnostic strategies for simple steatosis, steatohepatitis and hepatic fibrosis, followed by potential biomarkers associated with fat accumulation and mitochondrial stress. For mitochondrial stress indicators, we focused on fibroblast growth factor 21 (FGF21), growth differentiation factor 15 (GDF15), angiopoietin-related growth factor and mitochondrial-derived peptides. Each biomarker may not strongly indicate the severity of steatosis or steatohepatitis. Instead, multidimensional analysis of different groups of biomarkers based on pathogenic mechanisms may provide decisive diagnostic/prognostic information to develop a therapeutic plan for patients with NAFLD. For this purpose, mitochondrial stress indicators, such as FGF21 or GDF15, could be an important component in the multiplexed and contextual interpretation of NAFLD. Further validation of the integrative evaluation of mitochondrial stress indicators combined with other biomarkers is needed in the diagnosis/prognosis of NAFLD. (Gut Liver 2022;16:171-189)
\end{abstract}

Key Words: Non-alcoholic fatty liver disease; Biomarkers; Mitochondrial stress; Fibroblast growth factor 21; Growth differentiation factor 15

\section{INTRODUCTION}

Nonalcoholic fatty liver disease (NAFLD) is one of the most frequent causes of chronic liver disease worldwide, with an estimated prevalence ranging from $25 \%$ to $45 \%{ }^{1}$ The disease encompasses significant fat accumulation (simple steatosis) in the liver to more progressive steatohepatitis (nonalcoholic steatohepatitis, NASH), which may develop into fibrosis, cirrhosis, and even hepatocellular carcinoma. ${ }^{2,3}$ Simple hepatic steatosis has a benign nature, whereas NASH is more likely to progress to liver cirrhosis and cancer. ${ }^{4}$ Approximately $10 \%$ to $29 \%$ of patients with NASH develop cirrhosis within 10 years; of these, $4 \%$ to $27 \%$ develop liver cancer. ${ }^{5,6}$ Owing to its high prevalence and serious progression, reliable diagnostic and prognostic protocols for NAFLD have been in continuous demand. Until now, there is no "gold standard" for the noninvasive evaluation of patients with NAFLD to obtain essential information about disease severity and therapeutic plans.

The pathogenic features of NAFLD are quite complex and multifactorial. It was initially understood that the onset of NASH was due to sequential stimulation, referred to as the "two-hit theory." The first hit consists of obesity, sedentary lifestyle, metabolic overload, and insulin resistance. In particular, hyperinsulinemia accompanying obesity is a key factor in fat accumulation in hepatocytes, as well as increased lipid peroxidation. In the case of the second hit, oxidative stress and pro-inflammatory cytokine production contribute to hepatocellular injuries, resulting in the development of NASH. ${ }^{3,7,8}$ This is followed by a series of 
inflammatory reactions and fibrosis, which cause the death of hepatocytes. Progressive fibrosis and scarring of the liver leads to cirrhosis, which may progress to hepatocellular carcinoma in some patients. ${ }^{1}$ Subsequently, this hypothesis was modified into a "multiple parallel theory," which suggested that concurrent metabolic stimuli were responsible for tissue damage and disease progression.

Notably, it has been suggested that mitochondrial dysfunction and endoplasmic reticulum (ER) stress closely participate in the pathogenesis of alcoholic and nonalcoholic steatohepatitis. ${ }^{9-11}$ Calorie excess and less physical exercise increase lipid accumulation in the liver, eliciting reactive oxygen species (ROS) production from the cytosol and mitochondria. Higher ROS inflict prolonged stresses to mitochondria and the ER, accelerating further ROS generation from mitochondria and the ER. A positive feedback between oxidative stress and organellar dysfunction imposes detrimental consequences including inflammation and cytotoxicity. ${ }^{12-14}$

Koliaki et al. ${ }^{15}$ demonstrated that liver tissues from obese humans with or without fatty liver have higher mitochondrial mass and respiratory capacity as a metabolic adaptation named as "hepatic mitochondrial flexibility." However, those from NASH patients showed defective mitochondrial respiration with higher proton leak, augmented hepatic oxidative stress, and increased inflammatory responses. ${ }^{15}$ Structural abnormalities of mitochondria were also observed in liver tissues from NASH patients. ${ }^{12}$ All these evidences imply that mitochondrial dysfunction could be one of critical decisive factors in the progression into serious stages of NAFLD.

The sequential change in the pathophysiologic conditions of NAFLD can be detected by various kinds of biomarkers. ${ }^{17}$ Indeed, there have been a large number of studies that aimed to explain the clinical correlation between the levels of each serum biomarkers and the severity of NAFLD in patients. These studies have shown that circulating indicators reflect the different stresses involved in the pathogenesis of NAFLD. Fat-associated cytokines such as adiponectin, leptin, and retinol binding protein 4 (RBP4) indicate the existence of hyperlipidemic stress, whereas the elevation of aspartate and alanine transaminases are indicative of hepatocyte injury owing to steatohepatitis. Recently, a number of serum factors were identified as mitokines, which are proteins upregulated and secreted in response to mitochondrial stress induced by oxidative stress, mitochondrial proteostasis, and bioenergetic crisis. ${ }^{18,19}$ This is a composition of integrated stress responses, trying to overcome mitochondrial stress and protect against exacerbation of diseases. However, sustained and uncompensated stresses continue to upregulate mitochondrial factors and maintain their serum levels high. Mitochondrial biomarkers are known as a diagnostic indicator of mitochondrial diseases, ${ }^{20}$ but may also be an effective predictor of various metabolic and neurodegenerative diseases. ${ }^{21}$

Because of complicated pathophysiology and variable pattern of disease progression, the measurement of each single indicator cannot provide precise information for the diagnosis and prognosis of NAFLD. Instead, a multidimensional evaluation of dry (clinical parameters, imaging data, or functional measurement) and wet (biochemical or metabolic parameters in serum, urine, and tissue samples) biomarkers is necessary for the integrative interpretation of the status of the patient. Here, we have described the currently used diagnostic strategies for the different stages of NAFLD; simple steatosis, steatohepatitis, and hepatic fibrosis. Subsequently, we introduced potential serum biomarkers related to fat accumulation, mitochondrial stress, and inflammation, which may constitute effective components of a multiplexed biomarker analysis for NAFLD.

\section{CURRENT DIAGNOSTIC APPROACHES}

\section{Simple steatosis}

Conventional ultrasonography is the most commonly used diagnostic tool for simple hepatic steatosis, as it is well tolerated and widely available, with a reasonable cost. However, as ultrasonography can only detect steatosis with $>30 \%$ liver fat content, there is an underestimation of the number patients with $5 \%$ to $30 \%$ liver fat content. ${ }^{22}$ In addition, the diagnostic accuracy of steatosis is reduced in patients with obesity. ${ }^{23,24}$ Nevertheless, ultrasonography is still recommended as the first-step screening imaging modality for NAFLD. 25,26

As an alternative for the diagnosis of hepatic steatosis, the controlled attenuation parameter (CAP) is a noninvasive ultrasound-based method. CAP was reported to be able to detect $\geq 11 \%, \geq 33 \%$, and $\geq 66 \%$ steatosis of hepatocytes with high area under receiver operating characteristic (AUROCs) of 0.91, 0.95, and 0.89, respectively. ${ }^{27}$ Despite an acceptable correlation with the histological severity of fat accumulation, there are limitations to the use of CAP for the precise grading of steatosis when it is influenced by several covariates, including diabetes and body mass index. Regardless of the weak points, the proposed CAP cutoff value in moderate to severe steatosis $(>33 \%)$ is reliable $(>250 \mathrm{~dB} / \mathrm{m})$ and considered as a promising point-of-care diagnosis technique for the rapid quantification of steatosis in clinical practice.

Magnetic resonance spectroscopy (MRS) is a noninvasive, reproducible and accurate imaging technique, which 
is generally accepted as a noninvasive reference standard for the evaluation of liver fat. However, MRS has limited availability because it requires a sophisticated postprocessing method, and does not reflect the entire liver because it measures fat in small regions of interest. ${ }^{28}$ Magnetic resonance imaging-proton density fat fraction (MRI$\mathrm{PDFF}$ ) is also a promising noninvasive measurement of steatosis. MRI-PDFF has demonstrated robust correlation and equivalency with MRS. In addition, unlike MRS, MRIPDFF allows fat mapping of the entire liver. Recent studies have shown that MRI-PDFF was more sensitive than liver biopsy for the assessment of liver fat content ${ }^{29-31}$ because a wider area of the liver can be analyzed. Therefore, MRIPDFF is expected to be utilized in clinical trials as an end point. ${ }^{32}$ Furthermore, MRI-PDFF has shown better performance than CAP for the diagnosis of all grades of steatosis (AUROC 0.99 vs 0.85 , respectively; $\mathrm{p}=0.0091$ ) ${ }^{33,34}$ However, MRI-PDFF was unable to evaluate liver inflammation and fibrosis. ${ }^{35}$ In addition, careful co-localization of the "regions of interest" before and after treatment are critical for accurate follow-up measurements.

Many steatosis scoring systems based on serological indicators have been developed, including the fatty liver index, ${ }^{36}$ hepatic steatosis index, ${ }^{37}$ and NAFLD liver fat score. ${ }^{38}$ In one retrospective study, the diagnostic powers of these scoring systems were analyzed in a cohort of patients with the same extent of steatosis, and all were proven to be within an acceptable range (AUROC, 0.80 to 0.83 ). ${ }^{39}$ However, these scoring systems have not been applied in a clinical practice as they do not provide more useful information than that by conventional diagnostic approaches.

\section{Steatohepatitis}

Differential diagnosis of NASH from simple steatosis has clinical importance because compared to simple steatosis, NASH has a completely different clinical course and prognosis. NASH, particularly when combined with fibrosis, has a high risk of progression to cirrhosis and cancer; therefore, it is the main target disease requiring active intervention. Routinely tested serological parameters, such as alanine aminotransferase or aspartate aminotransferase, may indicate intrahepatic inflammation in NASH. However, as a fluctuating and non-specific liver injury marker, aminotransferases are limited in the estimation of NASH severity. ${ }^{40,41}$ Recently, new normal alanine aminotransferase cutoff values for NASH (30 U/L for men and $19 \mathrm{U} / \mathrm{L}$ for women) have been suggested, but they need to be validated in different races and clinical conditions. ${ }^{42,43}$

Circulating keratin-18 (CK-18) has been investigated widely for its usefulness in the diagnosis of NASH. ${ }^{44} \mathrm{CK}$ 18 is a major intermediate filament protein and a substrate of activated caspase-3 in hepatocytes. Serum CK-18 level has a higher predictive value for NASH (AUROC 0.83 , sensitivity 0.75 , and specificity 0.81 for a CK- 18 value of approximately $250 \mathrm{U} / \mathrm{L}){ }^{45-47}$ but it has several critical limitations: relatively low sensitivity, ${ }^{48}$ the lack of a commercially available kit, and difficulties in the selection of adequate cutoff values. ${ }^{49}$ There are other models to detect $\mathrm{NASH}$, including the NASH Test; however, most models are for selected subjects (e.g., patients with morbid obesity) and lack external validation. ${ }^{50-55}$

One of the novel strategies to detect patient at a risk of NASH is the "omics" approach. By using a lipidomicsbased analysis, eicosanoid metabolites of polyunsaturated fatty acid were proven to be candidates of predictive biomarkers for $\mathrm{NASH}^{56}{ }^{56}$ even though further validation is required. ${ }^{57}$ Several approaches have been proposed using genetic biomarkers, such as single nucleotide polymorphisms located in PNPLA3. For example, the NASH score and NASH ClinLipMet score involve PNPLA3 genotyping. ${ }^{58,59}$ The expression of microRNA, such as miR-122, is also under evaluation as a candidate for the noninvasive diagnosis of NASH ${ }^{60,61}$ Until now, owing to the limitations in clinical utility, none of the currently available serum markers could differentiate NASH from simple steatosis with the appropriate sensitivity and specificity.

\section{Hepatic fibrosis}

It has been shown that fibrosis is a major determinant of all causes of liver-related morbidity and mortality. ${ }^{62,63} \mathrm{As}$ a representative noninvasive dry biomarker, transient elastography (TE) is rapid, convenient, and widely validated diagnostic modality for the detection of liver stiffness. ${ }^{25,26}$ The diagnostic accuracy of TE for advanced fibrosis and cirrhosis has been reported as good ( $88 \%$ to $89 \%)$ and excellent (93\% to $96 \%$ ). ${ }^{64}$ Two-dimensional shear wave elastography (2D-SWE) is an ultrasound-based estimation of tissue stiffness that measures wave velocity. Compared to TE, 2D-SWE is considered to have better performance for the diagnosis of advanced fibrosis. In the subgroup containing 172 patients with NAFLD, diagnostic accuracies were $93 \%$ and $92 \%$ for advanced fibrosis and cirrhosis, respectively. ${ }^{65}$ In addition, 2D- and 3D-magnetic resonance elastography (MRE) showed high accuracy and reliability in liver fibrosis evaluation. ${ }^{66}$ Recent studies have shown that 3D-MRE at $40 \mathrm{~Hz}$ was superior to 2D-MRE at $60 \mathrm{~Hz}$, with AUROC values of 0.98 and 0.92 , respectively, for the detection for advanced fibrosis. ${ }^{67}$ It is suggested that $3 \mathrm{D}$ MRE may become a promising tool for the longitudinal changes in the assessment of fibrosis. However, the processing of 3D-MRE requires a much longer time and has not yet been applied in multicenter studies. Summarized 
characteristics of diagnostic modalities for fibrosis are presented in Table 1.

To evaluate the severity of advanced fibrosis, several scoring systems based on clinical and biochemical variables have been developed. The NAFLD fibrosis score (NFS), ${ }^{68}$ fibrosis-4 (FIB-4) index, ${ }^{69}$ aspartate aminotransferase-toplatelet ratio index (APRI), ${ }^{70}$ and BARD score ${ }^{71}$ are nonpatented biomarker panels. They showed high negative predictive values, so they can effectively exclude subjects without advanced fibrosis, thereby avoiding further unnecessary liver biopsies. However, they have poor positive predictive values and reduced accuracy for the detection of the earlier stage of fibrosis. Pro-C3 is a new serum biomarker derived exclusively from procollagen type III Nterminal peptide (PIIINP) turnover (synthesis and deposition). Increased level of PIIINP occurs as a consequence of tissue repair and fibrosis associated with advanced liver cirrhosis. ${ }^{72}$ A Pro-C3-based fibrosis algorithm consisting of ADAPT (age, presence of diabetes, Pro-C3, and platelet count) has recently shown superiority to APRI, FIB-4, and NFS for the identification of patients with serious fibrosis with NAFLD. ${ }^{73}$

Patented biomarker panels, including FibroTest ${ }^{\circledR},{ }^{74}$ Hepascore, ${ }^{75}$ enhanced liver fibrosis (ELF) test, ${ }^{76}$ and Fibrometer ${ }^{\circledR},{ }^{77}$ have shown marginal improvement in diagnostic competence over non-patented biomarkers. The ELF test (composed of hyaluronic acid, PIIINP, and a tissue inhibitor of metalloproteinase 1) was shown to have a good predictive value for advanced fibrosis with an AUROC of 0.90 , sensitivity of $80 \%$, and specificity of $90 \%$ when using a cutoff of $10.35 .^{76}$ Diagnostic algorithms for fibrosis are displayed in Table 2. From the perspective of longitudinal clinical outcomes, high NFS, FIB-4, APRI, and ELF scores have consistently been associated with an increased risk of cardiovascular- and liver-related mortality, and reinforcing the importance of these parameters in the prediction of long-term adverse clinical outcomes. ${ }^{78-80}$

The limitations of the current diagnostic strategies for NAFLD suggest that combinatorial interpretation of diverse dry and wet biomarkers could be efficient to improve accuracy and predictability. In particular, wet biomarker analysis to discriminate NASH from simple steatosis should provide early and decisive information in the management of NAFLD. For this purpose, multiplexed analysis of biomarkers reflecting different aspect of pathogenic processes, including fat accumulation, mitochondrial stress, and inflammation, is required. Here, we have introduced potential biomarkers that have been investigated in the past 10 to 20 years but are still not applicable due to insufficient validation.

\section{FAT BIOMARKERS}

\section{Leptin}

Leptin is considered an anorexigenic hormone that decreases food intake and induces energy expenditure. It is secreted from adipose tissues, and its circulating levels act as an indicator for energy reserves. It exerts its actions either through the activation of specific centers in the hypothalamus or directly in peripheral tissues. ${ }^{81}$

Besides its role in energy homeostasis, it contributes to skin repair, regulation of puberty and reproduction, and the prevention of lipotoxicity. As demonstrated by animal

Table 1. Comparisons of Diagnostic Modalities for Hepatic Fibrosis in NAFLD

\begin{tabular}{|c|c|c|c|c|}
\hline Modality & Parameter assessed & Cutoff values for advanced fibrosis & AUROC & Comment \\
\hline TE & $\begin{array}{l}\text { LSM using assessment of shear } \\
\text { wave velocity }\end{array}$ & $\begin{array}{l}\text { FibroScan }{ }^{\oplus} \\
\text { LSM: }<7.9 \text { kPa (in NAFLD): no advanced fibrosis } \\
\text { LSM: > } 9.6 \mathrm{kPa} \text { (in NAFLD): advanced fibrosis }\end{array}$ & $0.82-0.93$ & $\begin{array}{l}\text { Cheap } \\
\text { Reproducible } \\
\text { Use of XL probe may under-report LSM }\end{array}$ \\
\hline MRE & $\begin{array}{l}\text { LSM by shear wave measurement } \\
\text { using MRI sequence with motion } \\
\text { encoding gradient }\end{array}$ & MRE LSM: >4.15 kPa: advanced fibrosis & $0.90-0.95$ & $\begin{array}{l}\text { Expensive } \\
\text { Allows opportunistic assessment of LSM } \\
\text { during MRI } \\
\text { Mitigates issues of obesity or presence } \\
\text { of ascites }\end{array}$ \\
\hline ARFI & $\begin{array}{l}\text { LSM integrating elastography and } \\
\text { conventional B-mode ultraso- } \\
\text { nography }\end{array}$ & ARFI $>1.98 \mathrm{~m} / \mathrm{s}$ for $\mathrm{F} 4$ & $0.74-0.85$ & $\begin{array}{l}\text { Cheap } \\
\text { Uses conventional ultrasound machines } \\
\text { with modified algorithm }\end{array}$ \\
\hline SSI & $\begin{array}{l}\text { LSM integrating elastography and } \\
\text { conventional B-mode ultraso- } \\
\text { nography with simultaneous } \\
\text { assessment of several shear } \\
\text { waves of different velocity }\end{array}$ & SSI LSM >8.3 kPa & $0.83-0.92$ & $\begin{array}{l}\text { Cheap } \\
\text { Slightly higher reported accuracy for SSI } \\
\text { for advanced fibrosis when compared } \\
\text { with FibroScan }{ }^{\circledR}\end{array}$ \\
\hline
\end{tabular}

NAFLD, nonalcoholic fatty liver disease; AUROC, area under receiver operating characteristic; TE, transient elastography; MRE, magnetic resonance elastography; ARFI, acoustic resonance force impulse; SSI, supersonic shear wave imaging; LSM, liver stiffness measurement; MRI, magnetic resonance imaging. 
Table 2. Comparisons of Diagnostic Scoring Systems for Hepatic Fibrosis in NAFLD

\begin{tabular}{|c|c|c|c|c|}
\hline Score & Component & Formula & AUROC & Cutoff values for advanced fibrosis \\
\hline NFS & $\begin{array}{l}\text { Age } \\
\text { Hyperglycemia } \\
\text { BMI } \\
\text { Platelet count } \\
\text { Albumin } \\
\text { AST/ALT ratio }\end{array}$ & $\begin{array}{l}\mathrm{NFS}=-1.675+0.037 \times \text { age }(\mathrm{yr})+0.094 \times \mathrm{BMI} \\
\quad\left(\mathrm{kg} / \mathrm{m}^{2}\right)+1.13 \times \mathrm{IFG} / \mathrm{diabetes}(\mathrm{yes}=1, \mathrm{no}=0) \\
+0.99 \times \mathrm{AST} / \mathrm{ALT} \text { ratio- } 0.013 \times \text { platelet }\left(\times 10^{9} / \mathrm{L}\right) \\
-0.66 \times \text { albumin }(\mathrm{g} / \mathrm{dL})\end{array}$ & $0.81-0.85$ & $\begin{array}{l}\text { NFS (<-1.455): F0-F2 } \\
\text { NFS (1.455-0.675): indeterminate } \\
\text { NFS (>0.675): F3-F4 }\end{array}$ \\
\hline FibroTest $^{\circledR}$ & $\begin{array}{l}\text { Bilirubin } \\
\text { GGT } \\
\text { A2-macroglobulin } \\
\text { Haptoglobin } \\
\text { Apolipoprotein A1 }\end{array}$ & Proprietary formula & 0.86 & Fibrotest $>0.30$ : advanced fibrosis $(\geq F 3)$ \\
\hline APRI & $\begin{array}{l}\text { AST } \\
\text { Platelets }\end{array}$ & APRI=(AST/AST [ULN]]/platelet $\left(\times 10^{9} / \mathrm{L}\right)$ & $0.67-0.78$ & APRI >1: advanced fibrosis ( $\geq F 3)$ \\
\hline FIB-4 & $\begin{array}{l}\text { Age } \\
\text { AST } \\
\text { ALT } \\
\text { Platelets }\end{array}$ & 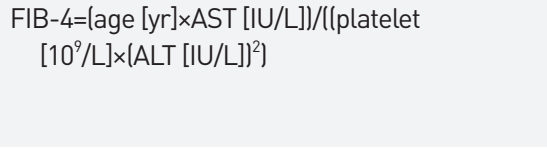 & $0.80-0.82$ & $\begin{array}{l}\text { FIB-4 (<1.30): F0-F1 } \\
\text { FIB-4 (>2.67): advanced fibrosis ( } \geq F 3 \text { ) }\end{array}$ \\
\hline BARD score & $\begin{array}{l}\text { BMI } \\
\text { AST/ALT ratio } \\
\text { DM }\end{array}$ & $\begin{array}{l}\text { Weighted sum of: } B M I \geq 28=1 \text { point, } \\
\text { AST } / A L T \text { ratio } \geq 0.8=2 \text {, } \\
\text { DM=1 point }\end{array}$ & $0.67-0.87$ & BARD score $>2$ : advanced fibrosis ( $\geq F 3$ ) \\
\hline ELF & $\begin{array}{l}\text { P3NP } \\
\text { TIMP-1 } \\
\text { Hyaluronic acid }\end{array}$ & $\begin{aligned} E L F & =-7.412+(\ln (\mathrm{HA}) \times 0.681)+(\ln (\mathrm{P} 3 \mathrm{NP}) \times 0.775) \\
& +(\ln (\mathrm{TIMP}-1) \times 0.494)\end{aligned}$ & 0.90 & ELF >0.3576: advanced fibrosis ( $\geq F 3$ ) \\
\hline FibroMeter for NAFLD & $\begin{array}{l}\text { Age } \\
\text { Body weight } \\
\text { Glycemia } \\
\text { Platelets } \\
\text { AST } \\
\text { ALT } \\
\text { Ferritin }\end{array}$ & $\begin{array}{l}0.4184 \text { glucose }(\mathrm{mmol} / \mathrm{L})+0.0701 \mathrm{AST}(\mathrm{U} / \mathrm{L}) \\
\quad+0.00008 \text { ferritin }(\mu \mathrm{g} / \mathrm{L})-0.0102 \text { platelet }(\mathrm{g} / \mathrm{L}) \\
\quad-0.0260 \mathrm{ALT}(\mathrm{U} / \mathrm{L})+0.0459 \text { body weight }(\mathrm{kg}) \\
\quad+0.0842 \text { age }(\mathrm{yr})+11.6226\end{array}$ & 0.94 & $\begin{array}{l}\text { FibroMeter for NAFLD >0.49: } \\
\text { significant fibrosis ( } \geq F 2 \text { ) }\end{array}$ \\
\hline
\end{tabular}

NAFLD, nonalcoholic fatty liver disease; AUROC, area under receiver operating characteristic; NFS, NAFLD fibrosis score; APRI, aspartate aminotransferase-to-platelet ratio index; FIB-4, fibrosis-4; ELF, enhanced liver fibrosis; BMI, body mass index; AST, aspartate aminotransferase; ALT, alanine aminotransferase; GGT, gamma-glutamyltransferase; IFG, impaired fasting glucose; ULN, upper limits of normal; DM, diabetes mellitus.

models, leptin prevents lipid accumulation at non-adipose sites. Leptin mediates its anti-lipogenic effect by lowering the sterol regulatory element-binding protein 1 level in the liver. Furthermore, leptin is involved in both innate and adaptive immunity. ${ }^{82,83}$

Because of compensatory change and receptor desensitization, serum leptin levels are significantly higher in patients with NAFLD than in control subjects, ${ }^{84-88}$ and they also correlated with the severity of hepatic steatosis. ${ }^{89}$ However, there are contrasting results that show no significant increase in serum leptin levels of patients with NAFLD. ${ }^{90,91}$ Leptin levels are slightly elevated during early cirrhotic stages but decline in advanced stages of the disease, mainly owing to the reduction in fat mass. ${ }^{92,93}$

\section{Adiponectin}

Adiponectin is solely secreted from adipocytes into the blood stream as three oligomeric complexes, namely, trimers, hexamers, and higher molecular weight multimers. ${ }^{94}$ The higher molecular weight form of adiponectin is responsible for insulin sensitivity and anti-inflammatory effects. Two receptors for adiponectin, known as AdipoR1 and AdipoR2, are expressed ubiquitously in many organs, with predominant expression in the skeletal muscle and liver, respectively. ${ }^{82,94}$ Adiponectin improves insulin sensitivities of hepatic and peripheral tissues and decreases total body fat. ${ }^{94}$

It also modulates endothelial cell inflammatory response by inhibiting nuclear factor $\kappa \mathrm{B}(\mathrm{NF}-\kappa \mathrm{B})$ activation and blocking the release of tumor necrosis factor- $\alpha$ (TNF- $\alpha$ ). In addition, adiponectin suppresses macrophage function, induces anti-inflammatory cytokines in leukocytes, and regulates lymphopoiesis. Adiponectin protects hepatocytes from the accumulation of triglycerides by either increasing $\beta$-oxidation or decreasing de novo synthesis of free fatty acids. $^{82}$

The accumulated data showed low serum levels of adiponectin in patients with NAFLD. ${ }^{95}$ Furthermore, hypoadiponectinemia was suggested to participate in the progression from steatosis to NASH. ${ }^{96}$ However, several 
studies have shown that adiponectin levels in patients with steatosis and NASH were not different from those in control groups. ${ }^{87,91}$ Meanwhile, adiponectin levels were increased in patients with liver cirrhosis and correlated with the severity of fibrosis. ${ }^{97-99}$ This pattern of alteration in serum adiponectin level is almost opposite to that of leptin and RBP4 in the progression of NAFLD.

\section{Retinol binding protein 4}

RBP4, mainly produced by the liver and visceral adipose tissues, plays a role in insulin resistance and inflammation in adipose and vascular tissues. Signaling receptor and transporter of retinol 6 (STRA6) has been suggested as a receptor for RBP4, but it is still unclear whether STRA6 mediates biological function of RBP4. ${ }^{2}$ High serum RBP4 have been consistently shown in patients with type 2 diabetes mellitus (T2DM), metabolic syndrome, and cardiovascular diseases (CVDs) along with obesity. Interestingly, exogenous RBP4 augments the secretion of inflammatory cytokines, including TNF- $\alpha$, interleukin 6 (IL-6), monocyte chemoattractant protein 1 (MCP-1), and interferon gamma (IFN- $\gamma$ ). Furthermore, the injection of RBP4 into normal mice induced insulin resistance, demonstrating that increased RBP4 may lead to diabetogenesis. ${ }^{100}$

Similar to T2DM and metabolic syndrome, there are positive correlations between circulating RBP4 levels and fatty liver diseases. ${ }^{101-103}$ In contrast, patients with liver cirrhosis $^{99}$ or chronic hepatitis $\mathrm{C}^{104}$ have reduced levels of RBP4, and some studies failed to find a relationship between RBP4, and steatosis and NASH. ${ }^{91,105-107}$ There exist confounding factors such as genetic susceptibilities, demographic characteristics, health status, and environmental factors, and most studies are based on observational studies with limited sample sizes. ${ }^{2,100}$

\section{MITOCHONDRIAL STRESS BIOMARKERS}

\section{Fibroblast growth factor 21}

Fibroblast growth factors (FGFs) are known to have multiple roles in development and signaling across a broad array of tissues. ${ }^{108}$ They are associated with various actions such as cell growth and differentiation along with embryonic development. ${ }^{109}$ The human/mouse FGF family consists of FGF1 to FGF23, with mouse FGF15 being an ortholog to human FGF19. ${ }^{110}$ FGF21 is an endocrine member of the FGF family that is primarily expressed in the liver, but is also synthesized in white adipose tissue (WAT), brown adipose tissue (BAT), the liver, pancreas, hypothalamus, skeletal muscles, and cardiac endothelial cells. 108,111,112

Most FGFs are secreted and interact with heparin sul- fate glycosaminoglycans (HSGAGs), which inhibits the dispersion of FGFs from their cell of origin. Signaling is produced after FGF peptides bind to one of the four FGF receptor subtypes (FGFR1-4). All these receptors are tyrosine receptor kinases that can dimerize after interaction with FGFs and initiate intracellular signaling. Unlike other FGFs, the endocrine FGF family, consisting of FGF19, FGF21, and FGF23, has a low affinity to HSGAGs and, therefore, diffuse into circulation to act on distal tissues. ${ }^{108}$ As FGF receptors are ubiquitously expressed, endocrine FGFs require a coreceptor for effective binding and signal transduction. $\beta$-Klotho (KLB) is the coreceptor that binds to the $\mathrm{C}$ terminus of FGF21. Then, $\mathrm{N}$ terminus of FGF21 interacts with FGFR, leading to an FGF21/FGFR/ KLB complex. Of the subtypes of FGFRs, FGFR1c has the highest binding affinity to FGF21, and the subsequent activation of FGFR/KLB increases the phosphorylation of FGF receptor substrate (FRS) $2 \alpha$ and extracellular-signalregulated kinase (ERK) $1 / 2$ in target tissues. ${ }^{108,109}$

The main physiological role of FGF21 is to maintain energy balance via the regulation of glucose and lipid metabolism. The plasma concentration of FGF21 is increased by various physical stressors, including intense exercise, cold exposure, and nutrient deprivation or overload. In response to starvation, FGF21 increases production of hepatic glucose and ketone bodies to sustain energy balance. ${ }^{111}$ WAT undergoes lipolysis by FGF21 to release glycerol and free fatty acids for the liver to use as gluconeogenesis and ketogenesis. Released fatty acids can activate nuclear hormone receptor peroxisome proliferator-activated receptor (PPAR) $\alpha$ in the liver, leading to increased FGF21 expression. ${ }^{108,112}$ Upregulated FGF21 further increases gluconeogenesis, $\beta$-oxidation, and ketogenesis in the liver.

Similar to starvation, the ketogenic diet increases FGF21 expression via PPAR $\alpha$ and promotes lipid oxidation and ketogenesis. FGF21 levels were notably increased by ketogenic diet in rodent studies and have been suggested as a crucial mediator of hepatic lipid metabolism during ketogenic states. ${ }^{113}$ In human studies, fructose diet strongly induces FGF21 expression through carbohydrate-responsive element-binding protein instead of starvation or ketogenic diet. ${ }^{114}$ Intriguingly, low-protein diet for 28 days in humans dramatically increased plasma FGF21 levels. A low-protein diet decreases essential amino acids, which leads to the activation of the amino acid sensor general control nonderepressible 2 (GCN2). Eukaryotic translation initiation factor $2 \alpha$ (eIF2 $\alpha$ ) is phosphorylated by GCN2 and later induces activating transcription factor 4 (ATF4). The Fgf21 promoter has multiple binding sites for ATF4, and this activation increases circulating and hepatic FGF21 levels. ${ }^{108}$

Cold exposure promotes heat generation in BAT and 
stimulates browning of WAT. FGF21 is induced by cold stimuli and plays a key role in adaptive thermogenesis in BAT, as well as beige fat after browning. Physical exercise increases the expression of FGF21 in the liver, which contributes to the beneficial metabolic effects of exercise. It remains unclear whether exercise induce FGF21 expression in skeletal muscle to act as a myokine. ${ }^{108,112}$ Meanwhile, FGF21 binds to FGFR in the hypothalamus to activate the hypothalamic-pituitary-adrenal axis for gluconeogenesis. In addition, KLB, acting as FGF21 coreceptor, is expressed in the hypothalamus, and FGF21 can cross the bloodbrain barrier. The role of FGF21 in the CNS has not been elucidated clearly. ${ }^{108}$

Recent studies have shown that FGF21 is induced by oxidative stress, ER stress, and mitochondrial dysfunction (Fig. 1); thus, it has been referred to as a stress hormone. In genetic mouse models with mitochondrial stress, the production of FGF21 increased from BAT, skeletal muscles, and cardiac tissues. ${ }^{108}$ Mitochondrial dysfunction resulting from defects in autophagy has been shown to induce FGF2 1 in a manner that is dependent on the eIF $2 \alpha-$ ATF4 axis. The increase in FGF21 expression resulting from mitochondrial stress is suggested as a compensatory mechanism to alleviate mitochondrial dysfunction. ${ }^{112}$ Consistently, pathophysiological states including T2DM, hepatic steatosis, steatohepatitis, and liver fibrosis have been associated with elevated levels of FGF21. ${ }^{108,111,112,115-119}$ Particularly, FGF21 reflects disease severity; thus, serum FGF21 is higher in NASH compared to simple steatosis. ${ }^{15,117}$ Circulating FGF21 level is also elevated in patients with diabetic nephropathy with a negative correlation between glomerular filtration rate and FGF21. ${ }^{111}$ Furthermore, serum FGF21 levels were increased significantly in patients with coronary heart disease and further elevated in patients with coronary heart disease and hypertension and diabetes. In these patients, adverse lipid profiles were associated with increased serum FGF21, which may have resulted from a compensatory response or resistance to FGF21. ${ }^{110}$

\section{Growth differentiation factor 15}

Growth differentiation factor 15 (GDF15) was first discovered as a remote member of the transforming growth factor $\beta$ (TGF- $\beta$ )/bone morphogenetic protein superfamily. ${ }^{120,121}$ Originally, GDF15 was described as an inhibitor of the production of TNF- $\alpha$ in lipopolysaccharide-stimulated macrophages and consequently named as macrophage inhibitory cytokine 1 . However, subsequent studies did not support its function of macrophage suppression. GDF15 is also referred to as placental transformation growth factor, prostate derived factor, placental bone morphogenetic protein, NSAID activated gene-1, and PL74. ${ }^{121}$ The GDF15 gene is located on chromosome 19, and it is composed of two exons separated by an intron. ${ }^{122}$ The GDF 15 protein is formed as a propeptide that homodimerizes and is later cleaved by a furin-like protease in the ER, to generate a mature dimer. The secreted mature dimer is then present in body fluids, such as the blood and cerebrospinal fluid. A high expression of GDF15 is found in the placenta and prostate, as well as in the kidney, liver, lung, pancreas, heart, brain, and skeletal muscles. ${ }^{12,123}$

Various stresses and tissue injuries upregulate GDF15

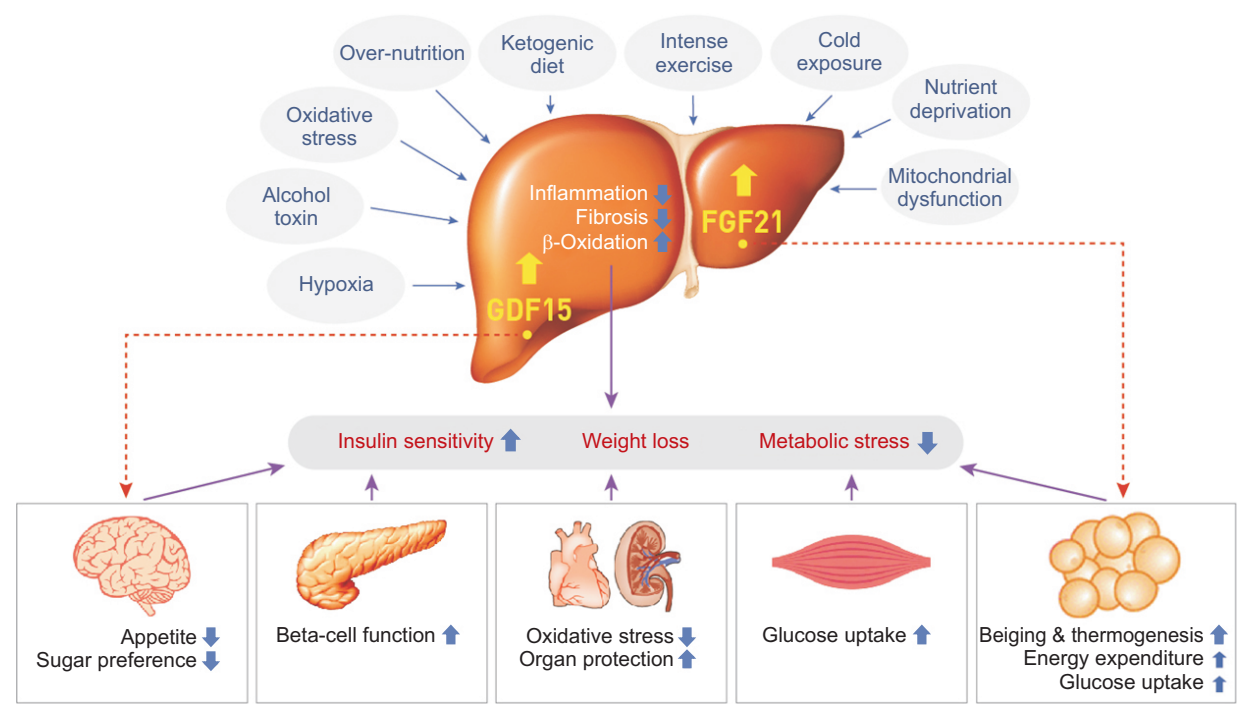

Fig. 1. Physiological regulation and functions of mitochondrial stress biomarkers. Physiological and pathophysiological conditions upregulating fibroblast growth factor 21 (FGF21) and growth differentiation factor 15 (GDF15) are listed above. FGF21 and/or GDF15 act on the liver, muscle, adipose tissue, brain, pancreatic islets, and other organs to relieve metabolic stress. 
expression and release from macrophages, cardiomyocytes, adipocytes, and vascular smooth muscle cells into circulation. ${ }^{121}$ Hypoxia or anoxia also increases GDF15 expression in colon carcinoma, glioblastoma, retinal pigment epithelial cells, and prostate cancer. In addition, GDF15 is strongly induced by exposure to pro-inflammatory cytokines, such as IL- $1 \beta$, TNF- $\alpha$, angiotensin II, macrophage colony stimulating factor, and TGF- $\beta .^{121,123}$ The GDF15 promoter has two p53-binding sites that allow the induction of GDF15 in response to various cellular stresses. In particular, it was suggested that p53 and ATF4, an upstream protein of ATF3, increases GDF15 transcription in patients with mitochondrial disease. PPAR $\gamma$ ligands induce GDF15 expression through the activation of the early growth response protein 1 . In addition, hypoxia-inducible factor- $1 \alpha$, NF$\kappa \mathrm{B}$, and Kruppel-like factor-4 are described as direct or indirect inducers of GDF15. ${ }^{123}$

GDF15 was originally thought to control food intake and body weight by interacting with the TGF- $\beta$ receptor, TGF $\beta$ R2. However, it was recently found that very small amounts of contaminated TGF- $\beta$ in commercial sources of GDF15 had a major influence on experimental results. Finally, a single transmembrane cell surface protein, glial cell-derived neurotrophic factor family receptor alphalike (GFRAL), was identified as the receptor for GDF15. GFRAIL is a member of the glial cell line-derived neurotrophic factor family, and it requires interaction with a coreceptor rearranged during transfection for activation. Although GDF15 is broadly expressed in many tissues, the expression of GFRAIL is limited to the brain area, with the highest levels found in the brainstem. ${ }^{120}$

Animal studies showed the physiologic role of GDF15 on the regulation of appetite and energy storage. GDF15knockout mice showed increased weight gain and adiposity associated with elevated food intake. ${ }^{124}$ In contrast, weight loss with decreased fat mass was observed in transgenic mice expressing murine GDF15 and was the result of a reduced appetite. This decrease in appetite was shown to be mediated by the direct control of GDF15 on feeding centers in the hypothalamus and brainstem. ${ }^{125}$ Meanwhile, transgenic mice expressing human GDF15 had a lower fat mass when consuming an equivalent intake of food to that of wild-type mice. ${ }^{126}$ However, there has been controversy owing to the different actions of murine and human GDF15.

Mitochondrial dysfunction is involved in the pathogenesis of insulin resistance, diabetes, CVDs, and neurodegenerative diseases. High levels of GDF15 in patients act as a protective mechanism, alleviating mitochondrial dysfunction through the induction of mitochondriarelated genes. The expression of PGC1 $\alpha$ is upregulated in
BAT, which suggests that GDF15 modulates mitochondrial functions such as biogenesis, thermogenesis, and fatty acid metabolism. ${ }^{123}$ Several studies have proposed that GDF15 has cardioprotective effects under pathological conditions. For example, cardiac-specific GDF15 transgenic mice displayed partial resistance to pressure overload-induced hypertrophy. In addition, ventricular dilation and heart failure was attenuated by the injection of recombinant GDF15 to a mouse model of heart failure. Thus, circulating GDF15 levels are suggested to have a crucial protective role against pathologic stressful conditions; however, the exact mechanism is still not clearly understood. ${ }^{123}$ Serum GDF levels were higher in simple steatosis, NASH, cirrhosis as well as viral hepatitis. ${ }^{127-129}$

\section{AGF (ANGPTL6)}

Angiopoietin-like proteins have 8 members (ANGPTL1 to 8) including angiopoietin-related growth factor (AGF), also known as ANGPTL6. AGF is a hepatokine involved in angiogenesis and epithelial cell proliferation, but also regulation of energy metabolism. ${ }^{130,131}$ AGF-knockout mice show obese phenotype caused by decreased energy consumption, while AGF-transgenic mice are resistant to diet-induced obesity with increased insulin sensitivity. ${ }^{132}$ In addition, exogenous AGF protein inhibits hepatic glucose production and decreased body weight. ${ }^{133}$

Despite its beneficial effects on metabolism, serum levels of AGF were elevated in polycystic ovarian syndrome, ${ }^{134}$ diabetes, ${ }^{135}$ and metabolic syndrome, ${ }^{136}$ similar to FGF21 or GDF15. Kim et al. ${ }^{137}$ observed that high fat diet increased hepatic AGF expression, that was reduced by exercise training. In primary rat hepatocytes, AGF expression was increased by leptin incubation accompanied with STAT3 phosphorylation, but the molecular mechanism regulating AGF expression remains unclear. Prospective cohort studies demonstrated that increased serum AGF levels precede the development of metabolic syndrome, having an independent predictive value. ${ }^{138}$

Interestingly, inhibition of mitochondrial oxidative phosphorylation increased expression of AGF accompanied with FGF21 expression in the adipose tissue. ${ }^{139}$ Recombinant AGF treatment also upregulated FGF21 expression and promoted mitochondrial $\beta$-oxidation. ${ }^{139}$ The role of AGF in the development of NAFLD has not been investigated, but elevated serum AGF level, similar to FGF21, could indicate mitochondrial stress and reflect the progression of NAFLD. ${ }^{140}$

\section{Mitochondrial-derived peptides}

Humanin is the first mitochondrial-derived peptide (MDP) discovered, and it has been shown to have multiple 
roles in different processes. It is encoded by an open reading frame (ORF) within the gene for the $16 \mathrm{~S}$ ribosomal subunit in the mitochondrial genome. ${ }^{141}$ Upon secretion, humanin is suggested to activate two different types of receptors. The first, formyl-peptide receptor-like-1 (FPRL1) and FPRL2, are G protein-coupled receptors and they induce signals through ERK pathways. The second receptor is a trimeric complex that consists of ciliary neurotrophic factor receptor, cytokine receptor WSX-1, and transmembrane glycoprotein gp130. This further activates Janus kinase, signal transducer and activator of transcription, and ERK. ${ }^{141,142}$

Humanin has a neuroprotective effect against amyloid- $\beta$, a suggested cause of Alzheimer's disease. A beneficial effect of humanin was demonstrated by amelioration of diazepam-induced memory dysfunction. ${ }^{143}$ It was later found that humanin binds to insulin-like growth factor binding protein 3 (IGFBP3) to exert its anti-apoptotic effects, as binding to IGFBP3 rescued the IGF-mediated cell survival. ${ }^{141,142}$ Cardiac ischemia-reperfusion injury was protected by humanin, which may be due to a decrease in ROS generation. ${ }^{144}$ In pancreatic $\beta$ cells, humanin reduced inflammatory response by decreasing TNF- $\alpha$, IL- $1 \beta$, and IFN- $\gamma$ and protected against apoptosis. Consistently, humanin augments the glucose-stimulated insulin release along with decreases in visceral fat and body weight. ${ }^{141}$ Serum humanin levels were found to be elevated in patients with preeclampsia, which may be a response to cardiovascular stress experienced. ${ }^{145}$ Interestingly, circulating humanin levels significantly decreased with age in both humans and rodents; moreover, the functional consequences remain unclear. ${ }^{146}$

There are six existing small humanin-like peptides (SHLP), SHLP1 to 6, which are positioned within the same $16 \mathrm{~S}$ rRNA gene where humanin is located. ${ }^{142}$ Similar to humanin, SHLP2 and SHLP3 have cytoprotective actions. SHLPs improve mitochondrial metabolism and reduce oxidative stress and apoptosis. In the presence of insulin, SHLP2 and SHLP3 accelerated the differentiation and insulin sensitivity of 3T3-L1 preadipocytes. Systemically, SHLP2 enhances the insulin-sensitizing effect by suppressing hepatic glucose production and increasing glucose disposal in peripheral tissues. Furthermore, SHLP2 treatment alone protected against amyloid $\beta_{1-42}$-induced cell death, which contributes to the pathogenesis of Alzheimer's disease. These neuroprotective and antioxidant actions of SHLPs may play a role in the regulation of aging. ${ }^{146}$

Mitochondrial ORF within the $12 \mathrm{~S}$ rRNA c (MOTS-c) is located in the 12S rRNA gene, which consists of 16 amino acid peptides. It is expressed in various tissues and also present in circulation, suggesting both cell-autonomous and cell-nonautonomous roles. ${ }^{142,147}$ MOTS-c improves insulin sensitivity and metabolic homeostasis via AMPactivated protein kinase (AMPK) activation as a result of increased 5-aminoimidazole-4-carboxamide ribonucleotide levels. The primary targets for MOTS-c are the skeletal muscle and adipose tissue. ${ }^{147}$ MOTS-c prevents high fat diet-induced obesity and insulin resistance owing to AMPK activation and glucose transporter GLUT4 upregulation in the skeletal muscle. ${ }^{148}$ Furthermore, MOTS-c augments physiological adaptation and tolerance to exercise, acting as a mitochondrial signal that mediates an exercise-induced mitohormesis response. ${ }^{149}$ MOTS-c increased carnitine shuttles and $\beta$-oxidation intermediates in fatty acid metabolism. In addition, MOTS-c caused significant decreases in visceral fat and hepatic steatosis. The metabolic effects of MOTS-c did not originate from reduced intake of calories or increased physical activities but were instead associated with an increase in body heat production. ${ }^{148}$ This suggested that MOTS-c has a potential role in the browning (beiging) of adipose tissue. ${ }^{147}$

Currently, it is difficult to correlate serum MDP concentration with different stages of NAFLD patients. However, based on results from in vitro and in vivo animal studies, we have inferred that metabolic stresses alter the serum levels of MDPs, which may be a reflection of the disease severity and prognosis in patients with NAFLD.

\section{INFLAMMATION BIOMARKER}

\section{Tumor necrosis factor- $\alpha$}

Inflammatory markers are known to be elevated in metabolic diseases; this is referred to as meta-inflammation. TNF- $\alpha$ is the first pro-inflammatory cytokine detected in adipose tissue and considered to be a pathogenic and prognostic biomarker of meta-inflammation. Accumulating evidence suggested that TNF- $\alpha$ expression in adipose tissue is increased in diabetic or obese animal and both serum TNF- $\alpha$ levels and its soluble receptors are positively correlated with visceral obesity. ${ }^{150}$ They demonstrated that genetic deletion of TNF- $\alpha$ enhances insulin sensitivity in diabetic $o b / o b$ or diet-induced obese mouse. In NAFLD patients, expression and secretion of TNF- $\alpha$ and its receptors increase along with the progression from simple steatosis to NASH and cirrhosis. ${ }^{151-153}$ Circulating TNF- $\alpha$ level was significantly elevated with the nonalcoholic steatosis score which reflects the grade of hepatic inflammation and damage. ${ }^{154}$ Polymorphism in the TNF- $\alpha$ promoter region and soluble TNF- $\alpha$ receptor were also higher in NASH patients than in those with simple steatosis or control. ${ }^{155,156}$ Furthermore, TNF- $\alpha$ was reported to be an independent predictor of advanced fibrosis in NASH patients. ${ }^{157,158}$ 
Based on the role of TNF- $\alpha$ in NAFLD progression, blockade of TNF- $\alpha$ signaling has been therapeutically approached to liver diseases. ${ }^{152}$ Pentoxifylline by inhibiting TNF- $\alpha$ production alleviates short-term survival of alcoholic hepatitis and hepatic injury of NASH. ${ }^{159,160}$

\section{Interleukin-6}

Elevated serum IL-6 levels have been reported in metabolic syndrome, CVDs and chronic pulmonary diseases. ${ }^{161}$ Visceral fat is known as a major site for IL-6 release in obese human, at least 3-times higher secretion compared with subcutaneous fat. ${ }^{162}$ Increased IL-6 is suggested to participate in the development of hepatic insulin resistance, since blocking IL-6 signaling improved insulin sensitivity in diet-induced obese mice. ${ }^{163}$ Further studies demonstrated that adipose tissue-derived IL- 6 aggravates hepatic insulin resistance by upregulating suppressor of cytokine signaling 3 , which is a critical negative regulator of the insulin and leptin signaling. ${ }^{164,165}$ Genetic deletion of IL- 6 attenuated lobular inflammation and expressions of TGF- $\beta$ and MCP-1 in diet-induced NASH mouse model. ${ }^{166}$ Similar to TNF- $\alpha$, IL- 6 shows a positive correlation with steatohepatitis and fibrosis. ${ }^{153,167}$ Higher serum levels of IL-6 associated with increased oxidative stress were correlated with the histological severities in the progression of NAFLD. ${ }^{15,168,169}$

\section{Chemokines}

Chemokine system is comprised of 50 chemokine ligands and 20 cognate receptors. Various cell types in the liver including leukocytes, hepatocytes, Kupffer cells, hepatic stellate cells, and sinusoidal endothelial cells can produce chemokines. ${ }^{170,171}$ CCL2, known as MCP-1, is a potent chemokine secreted upon inflammatory stimulus such as TNF- $\alpha$ or IL-6. In pathological conditions, CCL2 upregulation is associated with hepatic lipid accumulation and accelerates the development of NASH not only by recruiting immune cells but also producing inflammatory mediators. ${ }^{172,173}$ In addition, CCL2 plays a role in the recruitment and activation of hepatic stellate cell, leading to the development of liver fibrosis. ${ }^{173,174}$

Most of previous studies reported that circulating CCL2 levels are higher in NASH group compared to those in simple steatosis, demonstrating an importance for the conversion from fatty liver to pathologic inflammation. ${ }^{169,175}$ Other chemokines such as CCL5 (RANTES), CXCL8 (IL8) and CXCL9 (MIG) were also reported to be correlated with the NAFLD progression and elevated their serum levels in NASH and cirrhosis. ${ }^{157,176,177}$ Higher CXCL8 level with augmented oxidative stress was reported in NASH group compared to steatosis, but TNF- $\alpha$ and IL- 6 were not significantly increased in that study. ${ }^{178}$

\section{PERSPECTIVES ON DIAGNOSTIC STRATEGIES FOR NAFLD}

Based on their pathophysiologic molecular mechanisms, serum biomarkers can be classified into several groups. One such group is fat markers, including leptin, adiponectin, and RBP4 (Fig. 2). These are closely correlated with pathogenic adiposity: serum leptin and RBP4 tend to be increased in fatty liver and NASH, whereas adiponectin is downregulated (Table 3 ). In contrast, in some studies, no significant change is shown in leptin or adiponectin level in patients with NAFLD. Instead, the adiponectin/leptin

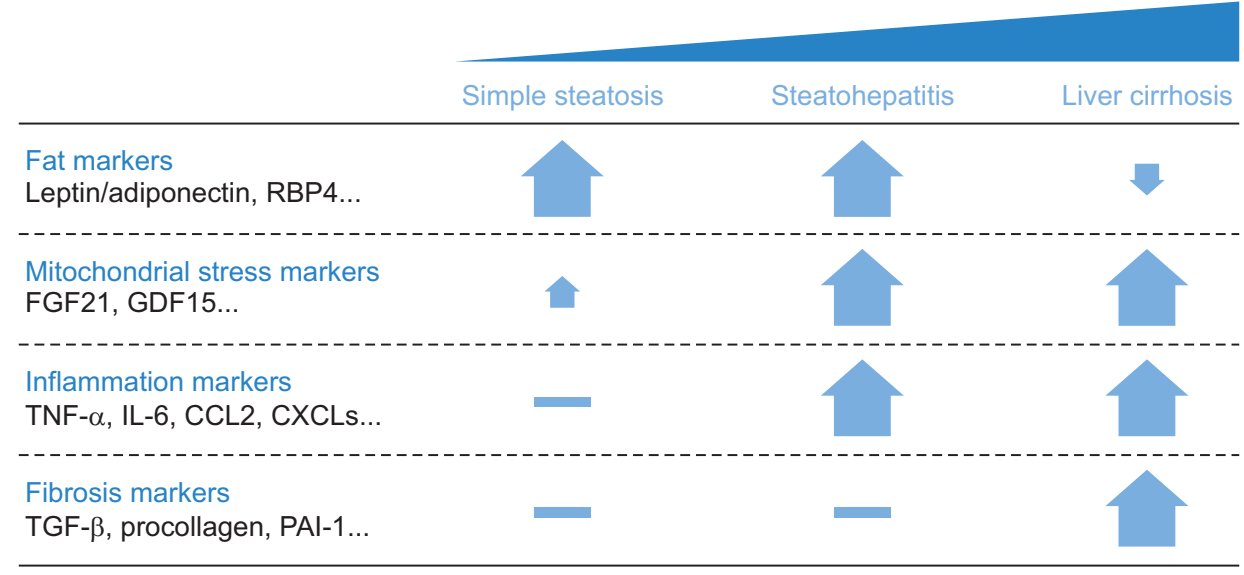

Fig. 2. Biomarkers for nonalcoholic fatty liver disease. Coordinated patterns of alterations in different types of serum markers during the progression of nonalcoholic fatty liver disease.

RBP4, retinol binding protein 4; FGF21, fibroblast growth factor 21; GDF15, growth differentiation factor 15; TNF-a, tumor necrosis factor a; IL-6, interleukin 6; CCL2, C-C motif chemokine ligand 2; CXCLs, C-x-C motif chemokine ligands; TGF- $\beta$, transforming growth factor $\beta$; PAl-1, plasminogen activator inhibitor-1. 


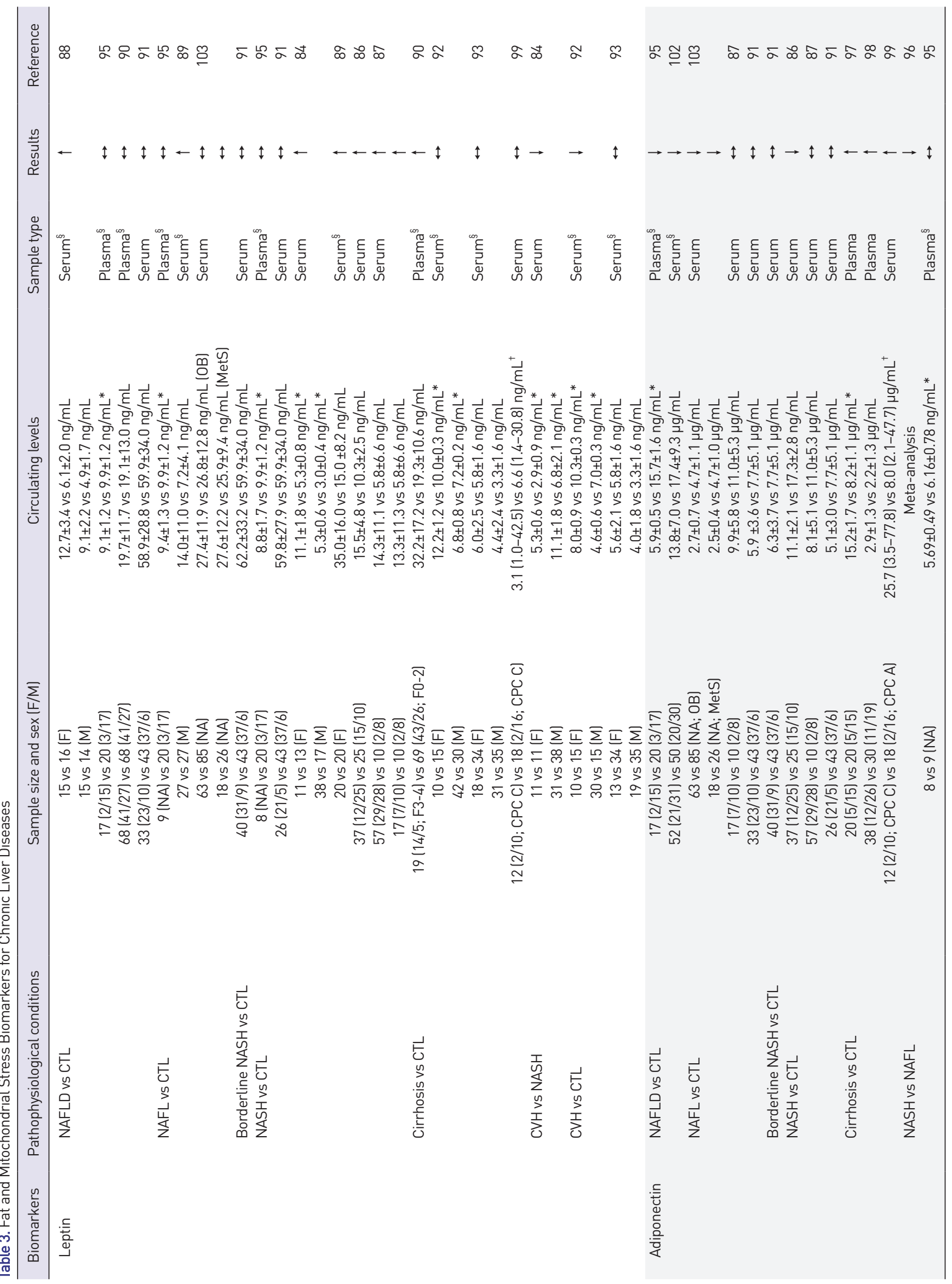




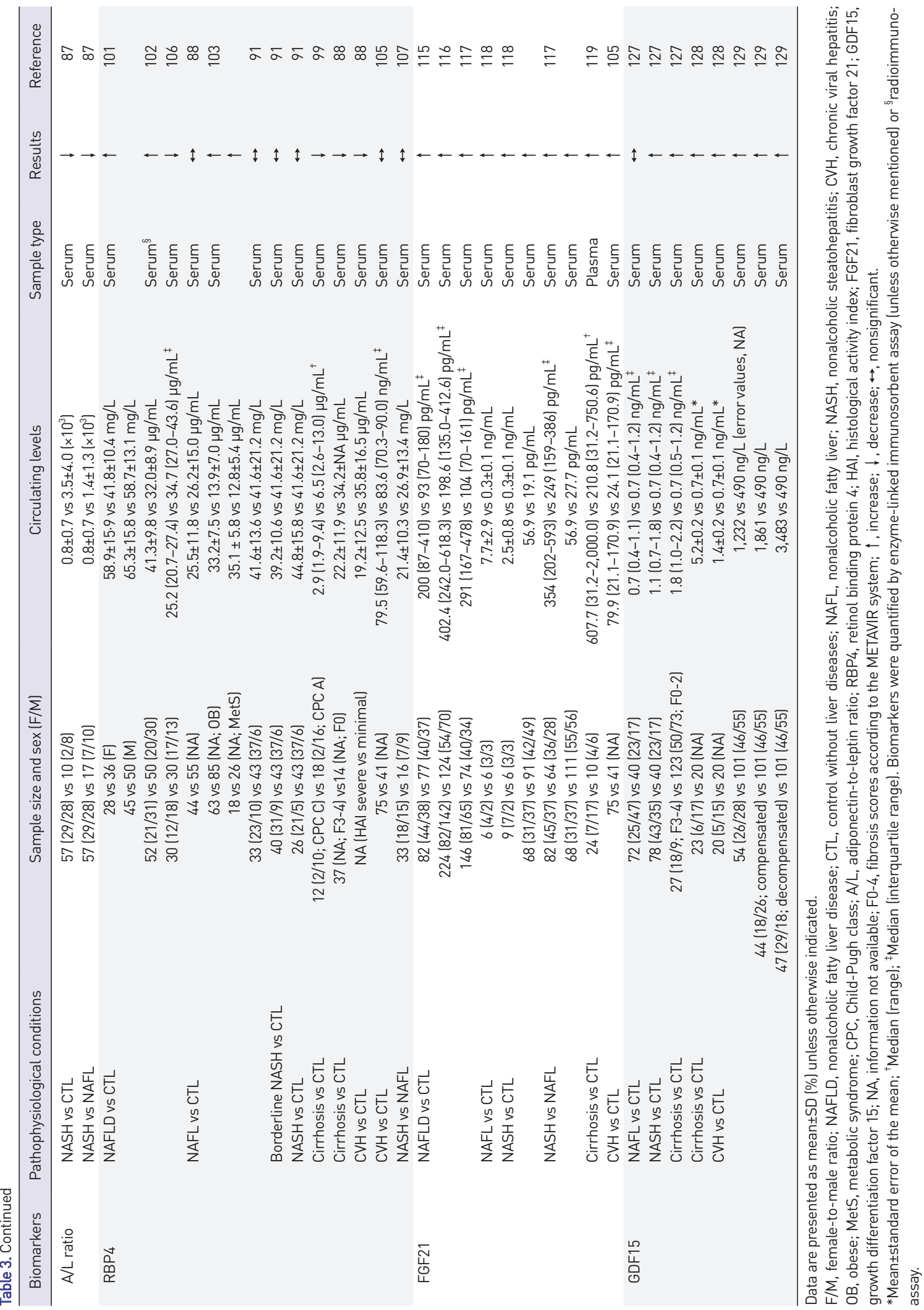


ratio showed a greater correlation with NASH than with each single marker. ${ }^{87}$ These alterations in leptin or adiponectin were attenuated or reversed in cirrhotic progression.

Mitochondrial stress indicators, such as FGF21 and GDF15, are emerging biomarkers that can be applied to the diagnosis of different metabolic or neurodegenerative diseases. ${ }^{179}$ AGF, MDPs, and other humoral factors could be additional candidates for mitochondrial stress biomarker. The accumulation of experimental evidence has supported their clinical applicability to the identification of pathologic stress levels. The diagnostic power of mitochondrial stress indicators may arise from the simultaneous measurement of other biomarkers. Along with the deteriorative advance in NAFLD, each serologic marker displays its own pattern of upward or downward changes, which are dependent on its involvement in disease progression. These variable trends in biomarkers may lead to incorrect diagnosis. In contrast, if we measure the concentration of different types of biomarkers at the same time, the variation in the kinetics of serum biomarkers may provide a novel clue to evaluate a patient's condition. The coordinated and structured pattern of changes in different types of biomarkers could enhance the estimation of NAFLD status and ability to predict its prognosis.

In conclusion, we have suggested that multidimensional biomarker analysis is required for the diagnosis of the different stages of NAFLD. Each biomarker introduced above may not be strongly correlated with the severity of NASH or liver fibrosis. Instead, integrative analyses of multiple groups of biomarkers should provide effective and critical information to select high-risk patients with NASH from patients with simple steatosis. To predict the development of NASH or fibrosis, we establish an estimating equation according to the correlation of biomarkers' level to disease progression. So far, there has not been sufficient data to draw a diagnostic algorithm for NAFLD. However, as more interpretation is performed with the equation, data could be feed forward to improve its accuracy. Deep learning process may further enhance its diagnostic performance and preciseness of analysis algorithm. Mitochondrial stress could be an important component in the multiplexed evaluation and contextual interpretation of NAFLD patients. These multidimensional analyses could effectively reduce unnecessary invasive diagnostic approaches in advance. Further investigations are required to validate the effectiveness of stress indicators in determining the diagnosis and prognosis of NAFLD.

\section{CONFLICTS OF INTEREST}

No potential conflict of interest relevant to this article was reported.

\section{ACKNOWLEDGEMENTS}

This work was supported by the Medical Research Center Program (2017R1A5A2015369), Bio \& Medical Technology Development Program (NRF-2020M3A9D8039920), and NRF Grant (2019R1A2C2084604) from the Ministry of Science and ICT, Republic of Korea.

\section{ORCID}

Eunha Chang https://orcid.org/0000-0002-8510-9368

Jae Seung Chang https://orcid.org/0000-0002-4047-1128 In Deok Kong https://orcid.org/0000-0002-9821-6103 Soon Koo Baik https://orcid.org/0000-0001-6245-2537 Moon Young Kim https://orcid.org/0000-0002-8566-2091 Kyu-Sang Park https://orcid.org/0000-0003-0322-9807

\section{REFERENCES}

1. Rinella ME. Nonalcoholic fatty liver disease: a systematic review. JAMA 2015;313:2263-2273.

2. Qiu Y, Wang S, Wan T, et al. Blood-based novel biomarkers for nonalcoholic steatohepatitis. Biomark Med 2018;12:501515.

3. Benedict $M$, Zhang $X$. Non-alcoholic fatty liver disease: an expanded review. World J Hepatol 2017;9:715-732.

4. Cohen JC, Horton JD, Hobbs HH. Human fatty liver disease: old questions and new insights. Science 2011;332:1519-1523.

5. Argo CK, Caldwell SH. Epidemiology and natural history of non-alcoholic steatohepatitis. Clin Liver Dis 2009;13:511531.

6. Starley BQ, Calcagno CJ, Harrison SA. Nonalcoholic fatty liver disease and hepatocellular carcinoma: a weighty connection. Hepatology 2010;51:1820-1832.

7. Giorgio V, Prono F, Graziano F, Nobili V. Pediatric non alcoholic fatty liver disease: old and new concepts on development, progression, metabolic insight and potential treatment targets. BMC Pediatr 2013;13:40.

8. Mota M, Banini BA, Cazanave SC, Sanyal AJ. Molecular mechanisms of lipotoxicity and glucotoxicity in nonalcoholic fatty liver disease. Metabolism 2016;65:1049-1061.

9. Mansouri A, Gattolliat CH, Asselah T. Mitochondrial dysfunction and signaling in chronic liver diseases. Gastroen- 
terology 2018;155:629-647.

10. Begriche K, Igoudjil A, Pessayre D, Fromenty B. Mitochondrial dysfunction in NASH: causes, consequences and possible means to prevent it. Mitochondrion 2006;6:1-28.

11. Trebicka J, Schierwagen R. Hepatic mitochondrial dysfunction in nonalcoholic steatohepatitis: read-out or reason? Hepatology 2016;63:1729-1732.

12. Sanyal AJ, Campbell-Sargent C, Mirshahi F, et al. Nonalcoholic steatohepatitis: association of insulin resistance and mitochondrial abnormalities. Gastroenterology 2001;120:11831192.

13. Machado MV, Diehl AM. Pathogenesis of nonalcoholic steatohepatitis. Gastroenterology 2016;150:1769-1777.

14. LéveilléM, Estall JL. Mitochondrial dysfunction in the transition from NASH to HCC. Metabolites 2019;9:233.

15. Koliaki C, Szendroedi J, Kaul K, et al. Adaptation of hepatic mitochondrial function in humans with non-alcoholic fatty liver is lost in steatohepatitis. Cell Metab 2015;21:739-746.

16. Sunny NE, Bril F, Cusi K. Mitochondrial adaptation in nonalcoholic fatty liver disease: novel mechanisms and treatment strategies. Trends Endocrinol Metab 2017;28:250-260.

17. Wong VW, Adams LA, de Lédinghen V, Wong GL, Sookoian S. Noninvasive biomarkers in NAFLD and NASH: current progress and future promise. Nat Rev Gastroenterol Hepatol 2018;15:461-478.

18. Kim KH, Jeong YT, Oh H, et al. Autophagy deficiency leads to protection from obesity and insulin resistance by inducing Fgf21 as a mitokine. Nat Med 2013;19:83-92.

19. Taylor RC, Berendzen KM, Dillin A. Systemic stress signalling: understanding the cell non-autonomous control of proteostasis. Nat Rev Mol Cell Biol 2014;15:211-217.

20. Davis RL, Liang C, Sue CM. A comparison of current serum biomarkers as diagnostic indicators of mitochondrial diseases. Neurology 2016;86:2010-2015.

21. Tezze C, Romanello V, Sandri M. FGF21 as modulator of metabolism in health and disease. Front Physiol 2019;10:419.

22. Paige JS, Bernstein GS, Heba E, et al. A pilot comparative study of quantitative ultrasound, conventional ultrasound, and MRI for predicting histology-determined steatosis grade in adult nonalcoholic fatty liver disease. AJR Am J Roentgenol 2017;208:W168-W177.

23. de Moura Almeida A, Cotrim HP, Barbosa DB, et al. Fatty liver disease in severe obese patients: diagnostic value of abdominal ultrasound. World J Gastroenterol 2008;14:14151418.

24. Mottin CC, Moretto M, Padoin AV, et al. The role of ultrasound in the diagnosis of hepatic steatosis in morbidly obese patients. Obes Surg 2004;14:635-637.

25. European Association for Study of Liver; Asociacion Latinoamericana para el Estudio del Higado. EASL-ALEH clinical practice guidelines: non-invasive tests for evaluation of liver disease severity and prognosis. J Hepatol 2015;63:237-264.

26. European Association for the Study of the Liver (EASL); European Association for the Study of Diabetes (EASD); European Association for the Study of Obesity (EASO). EASL-EASD-EASO clinical practice guidelines for the management of non-alcoholic fatty liver disease. J Hepatol 2016;64:1388-1402.

27. Sasso M, Beaugrand M, de Ledinghen V, et al. Controlled attenuation parameter (CAP): a novel VCTE ${ }^{\mathrm{Ts}}$ guided ultrasonic attenuation measurement for the evaluation of hepatic steatosis: preliminary study and validation in a cohort of patients with chronic liver disease from various causes. Ultrasound Med Biol 2010;36:1825-1835.

28. Di Martino M, Pacifico L, Bezzi M, et al. Comparison of magnetic resonance spectroscopy, proton density fat fraction and histological analysis in the quantification of liver steatosis in children and adolescents. World J Gastroenterol 2016;22:8812-8819.

29. Cui J, Philo L, Nguyen P, et al. Sitagliptin vs. placebo for nonalcoholic fatty liver disease: a randomized controlled trial. J Hepatol 2016;65:369-376.

30. Le TA, Chen J, Changchien C, et al. Effect of colesevelam on liver fat quantified by magnetic resonance in nonalcoholic steatohepatitis: a randomized controlled trial. Hepatology 2012;56:922-932.

31. Loomba R, Sirlin CB, Ang B, et al. Ezetimibe for the treatment of nonalcoholic steatohepatitis: assessment by novel magnetic resonance imaging and magnetic resonance elastography in a randomized trial (MOZART trial). Hepatology 2015;61:1239-1250.

32. Noureddin M, Lam J, Peterson MR, et al. Utility of magnetic resonance imaging versus histology for quantifying changes in liver fat in nonalcoholic fatty liver disease trials. Hepatology 2013;58:1930-1940.

33. Park CC, Nguyen P, Hernandez C, et al. Magnetic resonance elastography vs transient elastography in detection of fibrosis and noninvasive measurement of steatosis in patients with biopsy-proven nonalcoholic fatty liver disease. Gastroenterology 2017;152:598-607.e2.

34. Imajo K, Kessoku T, Honda Y, et al. Magnetic resonance imaging more accurately classifies steatosis and fibrosis in patients with nonalcoholic fatty liver disease than transient elastography. Gastroenterology 2016;150:626-637.e7.

35. Caussy C, Reeder SB, Sirlin CB, Loomba R. Noninvasive, quantitative assessment of liver fat by mri-pdff as an endpoint in NASH trials. Hepatology 2018;68:763-772.

36. Bedogni G, Bellentani S, Miglioli L, et al. The fatty liver index: a simple and accurate predictor of hepatic steatosis in the general population. BMC Gastroenterol 2006;6:33.

37. Lee JH, Kim D, Kim HJ, et al. Hepatic steatosis index: a simple screening tool reflecting nonalcoholic fatty liver disease. 
Dig Liver Dis 2010;42:503-508.

38. Kotronen A, Peltonen M, Hakkarainen A, et al. Prediction of non-alcoholic fatty liver disease and liver fat using metabolic and genetic factors. Gastroenterology 2009;137:865-872.

39. Fedchuk L, Nascimbeni F, Pais R, et al. Performance and limitations of steatosis biomarkers in patients with nonalcoholic fatty liver disease. Aliment Pharmacol Ther 2014;40:12091222.

40. Ipekci SH, Basaranoglu M, Sonsuz A. The fluctuation of serum levels of aminotransferase in patients with nonalcoholic steatohepatitis. J Clin Gastroenterol 2003;36:371.

41. Mofrad P, Contos MJ, Haque M, et al. Clinical and histologic spectrum of nonalcoholic fatty liver disease associated with normal ALT values. Hepatology 2003;37:1286-1292.

42. Kunde SS, Lazenby AJ, Clements RH, Abrams GA. Spectrum of NAFLD and diagnostic implications of the proposed new normal range for serum ALT in obese women. Hepatology 2005;42:650-656

43. Vilar-Gomez E, Yasells-Garcia A, Martinez-Perez Y, et al. Development and validation of a noninvasive prediction model for nonalcoholic steatohepatitis resolution after lifestyle intervention. Hepatology 2016;63:1875-1887.

44. Vilar-Gomez E, Chalasani N. Non-invasive assessment of non-alcoholic fatty liver disease: clinical prediction rules and blood-based biomarkers. J Hepatol 2018;68:305-315.

45. Kwok R, Tse YK, Wong GL, et al. Systematic review with meta-analysis: non-invasive assessment of non-alcoholic fatty liver disease--the role of transient elastography and plasma cytokeratin-18 fragments. Aliment Pharmacol Ther 2014;39:254-269.

46. Musso G, Gambino R, Cassader M, Pagano G. Metaanalysis: natural history of non-alcoholic fatty liver disease (NAFLD) and diagnostic accuracy of non-invasive tests for liver disease severity. Ann Med 2011;43:617-649.

47. Feldstein AE, Wieckowska A, Lopez AR, Liu YC, Zein NN, McCullough AJ. Cytokeratin-18 fragment levels as noninvasive biomarkers for nonalcoholic steatohepatitis: a multicenter validation study. Hepatology 2009;50:1072-1078.

48. Cusi K, Chang Z, Harrison S, et al. Limited value of plasma cytokeratin-18 as a biomarker for NASH and fibrosis in patients with non-alcoholic fatty liver disease. J Hepatol 2014;60:167-174.

49. Younossi ZM, Loomba R, Anstee QM, et al. Diagnostic modalities for nonalcoholic fatty liver disease, nonalcoholic steatohepatitis, and associated fibrosis. Hepatology 2018;68:349-360.

50. Anty R, Iannelli A, Patouraux S, et al. A new composite model including metabolic syndrome, alanine aminotransferase and cytokeratin-18 for the diagnosis of non-alcoholic steatohepatitis in morbidly obese patients. Aliment Pharmacol Ther 2010;32:1315-1322.
51. Campos GM, Bambha K, Vittinghoff E, et al. A clinical scoring system for predicting nonalcoholic steatohepatitis in morbidly obese patients. Hepatology 2008;47:1916-1923.

52. Ulitsky A, Ananthakrishnan AN, Komorowski R, et al. A noninvasive clinical scoring model predicts risk of nonalcoholic steatohepatitis in morbidly obese patients. Obes Surg 2010;20:685-691.

53. Lassailly G, Caiazzo R, Hollebecque A, et al. Validation of noninvasive biomarkers (FibroTest, SteatoTest, and NashTest) for prediction of liver injury in patients with morbid obesity. Eur J Gastroenterol Hepatol 2011;23:499-506.

54. Poynard T, Ratziu V, Charlotte F, et al. Diagnostic value of biochemical markers (NashTest) for the prediction of non alcoholo steato hepatitis in patients with non-alcoholic fatty liver disease. BMC Gastroenterol 2006;6:34.

55. Machado MV, Cortez-Pinto H. Non-invasive diagnosis of non-alcoholic fatty liver disease: a critical appraisal. J Hepatol 2013;58:1007-1019.

56. Loomba R, Quehenberger O, Armando A, Dennis EA. Polyunsaturated fatty acid metabolites as novel lipidomic biomarkers for noninvasive diagnosis of nonalcoholic steatohepatitis. J Lipid Res 2015;56:185-192.

57. Barr J, Caballería J, Martínez-Arranz I, et al. Obesity-dependent metabolic signatures associated with nonalcoholic fatty liver disease progression. J Proteome Res 2012;11:2521-2532.

58. Hyysalo J, MännistöVT, Zhou Y, et al. A population-based study on the prevalence of NASH using scores validated against liver histology. J Hepatol 2014;60:839-846.

59. Zhou Y, OrešičM, Leivonen $M$, et al. Noninvasive detection of nonalcoholic steatohepatitis using clinical markers and circulating levels of lipids and metabolites. Clin Gastroenterol Hepatol 2016;14:1463-1472.e6.

60. Becker PP, Rau M, Schmitt J, et al. Performance of serum microRNAs $-122,-192$ and -21 as biomarkers in patients with non-alcoholic steatohepatitis. PLoS One 2015;10:e0142661.

61. Pirola CJ, Fernández Gianotti T, Castaño GO, et al. Circulating microRNA signature in non-alcoholic fatty liver disease: from serum non-coding RNAs to liver histology and disease pathogenesis. Gut 2015;64:800-812.

62. Angulo P, Kleiner DE, Dam-Larsen S, et al. Liver fibrosis, but no other histologic features, is associated with long-term outcomes of patients with nonalcoholic fatty liver disease. Gastroenterology 2015;149:389-397.e10.

63. Hagström H, Nasr P, Ekstedt M, et al. Fibrosis stage but not NASH predicts mortality and time to development of severe liver disease in biopsy-proven NAFLD. J Hepatol 2017;67:1265-1273.

64. Friedrich-Rust M, Poynard T, Castera L. Critical comparison of elastography methods to assess chronic liver disease. Nat Rev Gastroenterol Hepatol 2016;13:402-411.

65. Herrmann E, de Lédinghen V, Cassinotto C, et al. Assess- 
ment of biopsy-proven liver fibrosis by two-dimensional shear wave elastography: an individual patient data-based meta-analysis. Hepatology 2018;67:260-272.

66. Xiao G, Zhu S, Xiao X, Yan L, Yang J, Wu G. Comparison of laboratory tests, ultrasound, or magnetic resonance elastography to detect fibrosis in patients with nonalcoholic fatty liver disease: a meta-analysis. Hepatology 2017;66:14861501.

67. Loomba R, Cui J, Wolfson T, et al. Novel 3D magnetic resonance elastography for the noninvasive diagnosis of advanced fibrosis in NAFLD: a prospective study. Am J Gastroenterol 2016;111:986-994.

68. Angulo P, Hui JM, Marchesini G, et al. The NAFLD fibrosis score: a noninvasive system that identifies liver fibrosis in patients with NAFLD. Hepatology 2007;45:846-854.

69. Sterling RK, Lissen E, Clumeck N, et al. Development of a simple noninvasive index to predict significant fibrosis in patients with HIV/HCV coinfection. Hepatology 2006;43:1317-1325.

70. Lin ZH, Xin YN, Dong QJ, et al. Performance of the aspartate aminotransferase-to-platelet ratio index for the staging of hepatitis C-related fibrosis: an updated meta-analysis. Hepatology 2011;53:726-736.

71. Harrison SA, Oliver D, Arnold HL, Gogia S, NeuschwanderTetri BA. Development and validation of a simple NAFLD clinical scoring system for identifying patients without advanced disease. Gut 2008;57:1441-1447.

72. Tanwar S, Trembling PM, Guha IN, et al. Validation of terminal peptide of procollagen III for the detection and assessment of nonalcoholic steatohepatitis in patients with nonalcoholic fatty liver disease. Hepatology 2013;57:103-111.

73. Daniels SJ, Leeming DJ, Eslam M, et al. ADAPT: an algorithm incorporating PRO-C3 accurately identifies patients with NAFLD and advanced fibrosis. Hepatology 2019;69:1075-1086.

74. Poynard T, Morra R, Halfon P, et al. Meta-analyses of FibroTest diagnostic value in chronic liver disease. BMC Gastroenterol 2007;7:40.

75. Adams LA, George J, Bugianesi E, et al. Complex non-invasive fibrosis models are more accurate than simple models in non-alcoholic fatty liver disease. J Gastroenterol Hepatol 2011;26:1536-1543.

76. Guha IN, Parkes J, Roderick P, et al. Noninvasive markers of fibrosis in nonalcoholic fatty liver disease: validating the European Liver Fibrosis Panel and exploring simple markers. Hepatology 2008;47:455-460.

77. Rosenberg WM, Voelker M, Thiel R, et al. Serum markers detect the presence of liver fibrosis: a cohort study. Gastroenterology 2004;127:1704-1713.

78. Kim D, Kim WR, Talwalkar JA, Kim HJ, Ehman RL. Advanced fibrosis in nonalcoholic fatty liver disease: non- invasive assessment with MR elastography. Radiology 2013;268:411-419.

79. Unalp-Arida A, Ruhl CE. Liver fibrosis scores predict liver disease mortality in the United States population. Hepatology 2017;66:84-95.

80. Parkes J, Roderick P, Harris S, et al. Enhanced liver fibrosis test can predict clinical outcomes in patients with chronic liver disease. Gut 2010;59:1245-1251.

81. van der Klaauw AA. Neuropeptides in obesity and metabolic disease. Clin Chem 2018;64:173-182.

82. Tsochatzis E, Papatheodoridis GV, Archimandritis AJ. The evolving role of leptin and adiponectin in chronic liver diseases. Am J Gastroenterol 2006;101:2629-2640.

83. Kelesidis T, Kelesidis I, Chou S, Mantzoros CS. Narrative review: the role of leptin in human physiology: emerging clinical applications. Ann Intern Med 2010;152:93-100.

84. Uygun A, Kadayifci A, Yesilova Z, et al. Serum leptin levels in patients with nonalcoholic steatohepatitis. Am J Gastroenterol 2000;95:3584-3589.

85. Tungtrongchitr R, Treeprasertsuk S, Ei NN, Thepouyporn A, Phonrat B, Huntrup A. Serum leptin concentrations in chronic hepatitis. J Med Assoc Thai 2006;89:490-499.

86. Yalniz M, Bahcecioglu IH, Ataseven H, et al. Serum adipokine and ghrelin levels in nonalcoholic steatohepatitis. Mediators Inflamm 2006;2006:34295.

87. Lemoine M, Ratziu V, Kim M, et al. Serum adipokine levels predictive of liver injury in non-alcoholic fatty liver disease. Liver Int 2009;29:1431-1438.

88. Huang XD, Fan Y, Zhang H, et al. Serum leptin and soluble leptin receptor in non-alcoholic fatty liver disease. World J Gastroenterol 2008;14:2888-2893.

89. Chitturi S, Farrell G, Frost L, et al. Serum leptin in NASH correlates with hepatic steatosis but not fibrosis: a manifestation of lipotoxicity? Hepatology 2002;36:403-409.

90. Angulo P, Alba LM, Petrovic LM, Adams LA, Lindor KD, Jensen MD. Leptin, insulin resistance, and liver fibrosis in human nonalcoholic fatty liver disease. J Hepatol 2004;41:943-949.

91. Kashyap SR, Diab DL, Baker AR, et al. Triglyceride levels and not adipokine concentrations are closely related to severity of nonalcoholic fatty liver disease in an obesity surgery cohort. Obesity (Silver Spring) 2009;17:1696-1701.

92. Testa R, Franceschini R, Giannini E, et al. Serum leptin levels in patients with viral chronic hepatitis or liver cirrhosis. J Hepatol 2000;33:33-37.

93. Comlekci A, Akpinar H, Yesil S, et al. Serum leptin levels in patients with liver cirrhosis and chronic viral hepatitis. Scand J Gastroenterol 2003;38:779-786.

94. Achari AE, Jain SK. Adiponectin, a therapeutic target for obesity, diabetes, and endothelial dysfunction. Int J Mol Sci 2017;18:1321. 
95. Pagano C, Soardo G, Esposito W, et al. Plasma adiponectin is decreased in nonalcoholic fatty liver disease. Eur J Endocrinol 2005;152:113-118.

96. Polyzos SA, Toulis KA, Goulis DG, Zavos C, Kountouras J. Serum total adiponectin in nonalcoholic fatty liver disease: a systematic review and meta-analysis. Metabolism 2011;60:313-326.

97. Tietge UJ, Böker KH, Manns MP, Bahr MJ. Elevated circulating adiponectin levels in liver cirrhosis are associated with reduced liver function and altered hepatic hemodynamics. Am J Physiol Endocrinol Metab 2004;287:E82-E89.

98. Sohara N, Takagi H, Kakizaki S, Sato K, Mori M. Elevated plasma adiponectin concentrations in patients with liver cirrhosis correlate with plasma insulin levels. Liver Int 2005;25:28-32.

99. Kalafateli M, Triantos C, Tsochatzis E, et al. Adipokines levels are associated with the severity of liver disease in patients with alcoholic cirrhosis. World J Gastroenterol 2015;21:3020-3029.

100. Zabetian-Targhi F, Mahmoudi MJ, Rezaei N, Mahmoudi M. Retinol binding protein 4 in relation to diet, inflammation, immunity, and cardiovascular diseases. Adv Nutr 2015;6:748-762.

101. Seo JA, Kim NH, Park SY, et al. Serum retinol-binding protein 4 levels are elevated in non-alcoholic fatty liver disease. Clin Endocrinol (Oxf) 2008;68:555-560.

102. Wu H, Jia W, Bao Y, et al. Serum retinol binding protein 4 and nonalcoholic fatty liver disease in patients with type 2 diabetes mellitus. Diabetes Res Clin Pract 2008;79:185-190.

103. Boyraz M, Cekmez F, Karaoglu A, Cinaz P, Durak M, Bideci A. Serum adiponectin, leptin, resistin and RBP4 levels in obese and metabolic syndrome children with nonalcoholic fatty liver disease. Biomark Med 2013;7:737-745.

104. Huang JF, Dai CY, Yu ML, et al. Serum retinol-binding protein 4 is inversely correlated with disease severity of chronic hepatitis C. J Hepatol 2009;50:471-478.

105. Kukla M, Berdowska A, Stygar D, et al. Serum FGF21 and RBP4 levels in patients with chronic hepatitis C. Scand J Gastroenterol 2012;47:1037-1047.

106. Schina M, Koskinas J, Tiniakos D, et al. Circulating and liver tissue levels of retinol-binding protein-4 in non-alcoholic fatty liver disease. Hepatol Res 2009;39:972-978.

107. Alkhouri N, Lopez R, Berk M, Feldstein AE. Serum retinolbinding protein 4 levels in patients with nonalcoholic fatty liver disease. J Clin Gastroenterol 2009;43:985-989.

108. BonDurant LD, Potthoff MJ. Fibroblast growth factor 21: a versatile regulator of metabolic homeostasis. Annu Rev Nutr 2018;38:173-196.

109. Fisher FM, Maratos-Flier E. Understanding the physiology of FGF21. Annu Rev Physiol 2016;78:223-241.

110. Itoh N. FGF21 as a hepatokine, adipokine, and myokine in metabolism and diseases. Front Endocrinol (Lausanne) 2014;5:107.

111. Gómez-Sámano MÁ, Grajales-Gómez M, Zuarth-Vázquez JM, et al. Fibroblast growth factor 21 and its novel association with oxidative stress. Redox Biol 2017;11:335-341.

112. Kim KH, Lee MS. FGF21 as a stress hormone: the roles of FGF21 in stress adaptation and the treatment of metabolic diseases. Diabetes Metab J 2014;38:245-251.

113. Badman MK, Pissios P, Kennedy AR, Koukos G, Flier JS, Maratos-Flier E. Hepatic fibroblast growth factor 21 is regulated by PPARalpha and is a key mediator of hepatic lipid metabolism in ketotic states. Cell Metab 2007;5:426-437.

114. Dushay JR, Toschi E, Mitten EK, Fisher FM, Herman MA, Maratos-Flier E. Fructose ingestion acutely stimulates circulating FGF21 levels in humans. Mol Metab 2014;4:51-57.

115. Yilmaz Y, Eren F, Yonal O, et al. Increased serum FGF21 levels in patients with nonalcoholic fatty liver disease. Eur J Clin Invest 2010;40:887-892.

116. Li H, Fang Q, Gao F, et al. Fibroblast growth factor 21 levels are increased in nonalcoholic fatty liver disease patients and are correlated with hepatic triglyceride. J Hepatol 2010;53:934-940.

117. Shen J, Chan HL, Wong GL, et al. Non-invasive diagnosis of non-alcoholic steatohepatitis by combined serum biomarkers. J Hepatol 2012;56:1363-1370.

118. Dushay J, Chui PC, Gopalakrishnan GS, et al. Increased fibroblast growth factor 21 in obesity and nonalcoholic fatty liver disease. Gastroenterology 2010;139:456-463.

119. Ruiz-Margáin A, Pohlmann A, Ryan P, et al. Fibroblast growth factor 21 is an early predictor of acute-on-chronic liver failure in critically ill patients with cirrhosis. Liver Transpl 2018;24:595-605.

120. Emmerson PJ, Duffin KL, Chintharlapalli S, Wu X. GDF15 and growth control. Front Physiol 2018;9:1712.

121. Adela R, Banerjee SK. GDF-15 as a target and biomarker for diabetes and cardiovascular diseases: a translational prospective. J Diabetes Res 2015;2015:490842.

122. Corre J, Hébraud B, Bourin P. Concise review: growth differentiation factor 15 in pathology: a clinical role? Stem Cells Transl Med 2013;2:946-952.

123. Fujita Y, Taniguchi Y, Shinkai S, Tanaka M, Ito M. Secreted growth differentiation factor 15 as a potential biomarker for mitochondrial dysfunctions in aging and age-related disorders. Geriatr Gerontol Int 2016;16 Suppl 1:17-29.

124. Tsai VW, Macia L, Johnen H, et al. TGF-b superfamily cytokine MIC-1/GDF15 is a physiological appetite and body weight regulator. PLoS One 2013;8:e55174.

125. Johnen H, Lin S, Kuffner T, et al. Tumor-induced anorexia and weight loss are mediated by the TGF-beta superfamily cytokine MIC-1. Nat Med 2007;13:1333-1340.

126. Chrysovergis K, Wang X, Kosak J, et al. NAG-1/GDF-15 
prevents obesity by increasing thermogenesis, lipolysis and oxidative metabolism. Int J Obes (Lond) 2014;38:1555-1564.

127. Koo BK, Um SH, Seo DS, et al. Growth differentiation factor 15 predicts advanced fibrosis in biopsy-proven non-alcoholic fatty liver disease. Liver Int 2018;38:695-705.

128. Halim MH, Abdulla NA, Kamel A, El Maksoud NA, Ragab HM. Significance of growth differentiation factor 15 in chronic HCV patients. J Genet Eng Biotechnol 2017;15:403407.

129. Lee ES, Kim SH, Kim HJ, Kim KH, Lee BS, Ku BJ. Growth differentiation factor 15 predicts chronic liver disease severity. Gut Liver 2017;11:276-282.

130. Oike Y, Ito Y, Maekawa H, et al. Angiopoietin-related growth factor (AGF) promotes angiogenesis. Blood 2004;103:37603765.

131. Oike Y, Yasunaga K, Ito Y, et al. Angiopoietin-related growth factor (AGF) promotes epidermal proliferation, remodeling, and regeneration. Proc Natl Acad Sci U S A 2003;100:94949499.

132. Oike Y, Akao M, Yasunaga K, et al. Angiopoietin-related growth factor antagonizes obesity and insulin resistance. Nat Med 2005;11:400-408.

133. Kitazawa M, Ohizumi Y, Oike Y, Hishinuma T, Hashimoto S. Angiopoietin-related growth factor suppresses gluconeogenesis through the Akt/forkhead box class O1-dependent pathway in hepatocytes. J Pharmacol Exp Ther 2007;323:787793.

134. Boztosun A, Deveci K, Klçl F, Söylemez MS, Muhtaroğlu S, Müderris II. Serum levels of angiopoietin-related growth factor (AGF) are increased in polycystic ovary syndrome. J Investig Med 2012;60:813-817.

135. Ebert T, Bachmann A, Lössner U, et al. Serum levels of angiopoietin-related growth factor in diabetes mellitus and chronic hemodialysis. Metabolism 2009;58:547-551.

136. Namkung J, Koh SB, Kong ID, Choi JW, Yeh BI. Serum levels of angiopoietin-related growth factor are increased in metabolic syndrome. Metabolism 2011;60:564-568.

137. Kim MJ, Namkung J, Chang JS, Kim SJ, Park KS, Kong ID. Leptin regulates the expression of angiopoietin-like 6. Biochem Biophys Res Commun 2018;502:397-402.

138. Namkung J, Sohn JH, Chang JS, et al. Increased serum angiopoietin-like 6 ahead of metabolic syndrome in a prospective cohort study. Diabetes Metab J 2019;43:521-529.

139. Kang SG, Yi HS, Choi MJ, et al. ANGPTL6 expression is coupled with mitochondrial OXPHOS function to regulate adipose FGF21. J Endocrinol 2017;233:105-118.

140. Erkan G, Muratoglu S, Ercin U, Bilgihan A. Angiopoietinlike protein 2 and angiopoietin-like protein 6 levels in patients with nonalcoholic fatty liver disease. Arch Med Sci 2018;14:781-787.

141. Yen K, Lee C, Mehta H, Cohen P. The emerging role of the mitochondrial-derived peptide humanin in stress resistance. J Mol Endocrinol 2013;50:R11-R19.

142. Kim SJ, Xiao J, Wan J, Cohen P, Yen K. Mitochondrially derived peptides as novel regulators of metabolism. J Physiol 2017;595:6613-6621.

143. Murakami M, Nagahama M, Maruyama T, Niikura T. Humanin ameliorates diazepam-induced memory deficit in mice. Neuropeptides 2017;62:65-70.

144. Muzumdar RH, Huffman DM, Calvert JW, et al. Acute humanin therapy attenuates myocardial ischemia and reperfusion injury in mice. Arterioscler Thromb Vasc Biol 2010;30:1940-1948.

145. Nikolakopoulos P, Tzimagiorgis G, Goulis DG, Chatzopoulou F, Zepiridis L, Vavilis D. Serum humanin concentrations in women with pre-eclampsia compared to women with uncomplicated pregnancies. J Matern Fetal Neonatal Med 2018;31:305-311.

146. Cobb LJ, Lee C, Xiao J, et al. Naturally occurring mitochondrial-derived peptides are age-dependent regulators of apoptosis, insulin sensitivity, and inflammatory markers. Aging (Albany NY) 2016;8:796-809.

147. Lee C, Kim KH, Cohen P. MOTS-c: a novel mitochondrialderived peptide regulating muscle and fat metabolism. Free Radic Biol Med 2016;100:182-187.

148. Lee C, Zeng J, Drew BG, et al. The mitochondrial-derived peptide MOTS-c promotes metabolic homeostasis and reduces obesity and insulin resistance. Cell Metab 2015;21:443454.

149. Merry TL, Ristow M. Mitohormesis in exercise training. Free Radic Biol Med 2016;98:123-130.

150. Uysal KT, Wiesbrock SM, Marino MW, Hotamisligil GS. Protection from obesity-induced insulin resistance in mice lacking TNF-alpha function. Nature 1997;389:610-614.

151. Crespo J, Cayón A, Fernández-Gil P, et al. Gene expression of tumor necrosis factor alpha and TNF-receptors, p55 and p75, in nonalcoholic steatohepatitis patients. Hepatology 2001;34:1158-1163.

152. Tilg H, Diehl AM. Cytokines in alcoholic and nonalcoholic steatohepatitis. N Engl J Med 2000;343:1467-1476.

153. Kugelmas M, Hill DB, Vivian B, Marsano L, McClain CJ. Cytokines and NASH: a pilot study of the effects of lifestyle modification and vitamin E. Hepatology 2003;38:413-419.

154. Manco M, Marcellini M, Giannone G, Nobili V. Correlation of serum TNF-alpha levels and histologic liver injury scores in pediatric nonalcoholic fatty liver disease. Am J Clin Pathol 2007;127:954-960.

155. Tokushige K, Takakura M, Tsuchiya-Matsushita N, Taniai M, Hashimoto E, Shiratori K. Influence of TNF gene polymorphisms in Japanese patients with NASH and simple steatosis. J Hepatol 2007;46:1104-1110.

156. Hui JM, Hodge A, Farrell GC, Kench JG, Kriketos A, George 
J. Beyond insulin resistance in NASH: TNF-alpha or adiponectin? Hepatology 2004;40:46-54.

157. Jarrar MH, Baranova A, Collantes R, et al. Adipokines and cytokines in non-alcoholic fatty liver disease. Aliment Pharmacol Ther 2008;27:412-421.

158. Lesmana CR, Hasan I, Budihusodo U, et al. Diagnostic value of a group of biochemical markers of liver fibrosis in patients with non-alcoholic steatohepatitis. J Dig Dis 2009;10:201206.

159. Akriviadis E, Botla R, Briggs W, Han S, Reynolds T, Shakil O. Pentoxifylline improves short-term survival in severe acute alcoholic hepatitis: a double-blind, placebo-controlled trial. Gastroenterology 2000;119:1637-1648.

160. Lee YM, Sutedja DS, Wai CT, et al. A randomized controlled pilot study of Pentoxifylline in patients with non-alcoholic steatohepatitis (NASH). Hepatol Int 2008;2:196-201.

161. Wannamethee SG, Whincup PH, Rumley A, Lowe GD. Inter-relationships of interleukin-6, cardiovascular risk factors and the metabolic syndrome among older men. J Thromb Haemost 2007;5:1637-1643.

162. Fontana L, Eagon JC, Trujillo ME, Scherer PE, Klein S. Visceral fat adipokine secretion is associated with systemic inflammation in obese humans. Diabetes 2007;56:1010-1013.

163. Klover PJ, Clementi AH, Mooney RA. Interleukin-6 depletion selectively improves hepatic insulin action in obesity. Endocrinology 2005;146:3417-3427.

164. Sabio G, Das M, Mora A, et al. A stress signaling pathway in adipose tissue regulates hepatic insulin resistance. Science 2008;322:1539-1543

165. Yang Z, Hulver M, McMillan RP, et al. Regulation of insulin and leptin signaling by muscle suppressor of cytokine signaling 3 (SOCS3). PLoS One 2012;7:e47493.

166. Mas E, Danjoux M, Garcia V, Carpentier S, Ségui B, Levade T. IL-6 deficiency attenuates murine diet-induced nonalcoholic steatohepatitis. PLoS One 2009;4:e7929.

167. Wieckowska A, Papouchado BG, Li Z, Lopez R, Zein NN, Feldstein AE. Increased hepatic and circulating interleukin-6 levels in human nonalcoholic steatohepatitis. Am J Gastroenterol 2008;103:1372-1379.

168. Kumar R, Prakash S, Chhabra S, et al. Association of proinflammatory cytokines, adipokines \& oxidative stress with insulin resistance \& non-alcoholic fatty liver disease. Indian J Med Res 2012;136:229-236.

169. Kar S, Paglialunga S, Jaycox SH, Islam R, Paredes AH. Assay validation and clinical performance of chronic inflammatory and chemokine biomarkers of NASH fibrosis. PLoS One 2019;14:e0217263.

170. Saiman Y, Friedman SL. The role of chemokines in acute liver injury. Front Physiol 2012;3:213.

171. Roh YS, Seki E. Chemokines and chemokine receptors in the development of NAFLD. Adv Exp Med Biol 2018;1061:4553.

172. Rull A, Rodríguez F, Aragonès G, et al. Hepatic monocyte chemoattractant protein-1 is upregulated by dietary cholesterol and contributes to liver steatosis. Cytokine 2009;48:273279.

173. Greco D, Kotronen A, Westerbacka J, et al. Gene expression in human NAFLD. Am J Physiol Gastrointest Liver Physiol 2008;294:G1281-G1287.

174. Marra F, Romanelli RG, Giannini C, et al. Monocyte chemotactic protein-1 as a chemoattractant for human hepatic stellate cells. Hepatology 1999;29:140-148.

175. Haukeland JW, Damås JK, Konopski Z, et al. Systemic inflammation in nonalcoholic fatty liver disease is characterized by elevated levels of CCL2. J Hepatol 2006;44:11671174.

176. Pan X, Chiwanda Kaminga A, Liu A, Wen SW, Chen J, Luo J. Chemokines in non-alcoholic fatty liver disease: a systematic review and network meta-analysis. Front Immunol 2020;11:1802

177. Bahcecioglu IH, Yalniz M, Ataseven H, et al. Levels of serum hyaluronic acid, TNF-alpha and IL-8 in patients with nonalcoholic steatohepatitis. Hepatogastroenterology 2005;52:1549-1553.

178. Torer N, Ozenirler S, Yucel A, Bukan N, Erdem O. Importance of cytokines, oxidative stress and expression of BCL-2 in the pathogenesis of non-alcoholic steatohepatitis. Scand J Gastroenterol 2007;42:1095-1101.

179. Ajaz S, McPhail MJ, Gnudi L, et al. Mitochondrial dysfunction as a mechanistic biomarker in patients with nonalcoholic fatty liver disease (NAFLD). Mitochondrion 2021;57:119-130 